\title{
Pulsed Corona Plasma Technology for Treating VOC Emissions from Pulp Mills
}

\author{
Alexei V. Saveliev ${ }^{\mathrm{i}}$, Lawrence A. Kennedy ${ }^{\mathrm{i}}$, Alexander Fridman ${ }^{\mathrm{ii}}$, Alexander Gutsol ${ }^{\mathrm{ii}}$, Sergey Korobtsev ${ }^{\mathrm{iii}}$, \\ Valery Shiryaevsky ${ }^{\text {iii }}$ and Dmitry Medvedev ${ }^{\text {iii }}$ \\ (i)Department of Mechanical and Industrial Engineering, University of Illinois at Chicago \\ (ii)Drexel Plasma Institute, Drexel University \\ (iii)ECOS Ltd., RRC “Kurchatov Institute”, Moscow, Russia
}

\begin{abstract}
Under the DOE Office of Industrial Technologies Forest Products program various plasma technologies were evaluated under project FWP 49885 "Experimental Assessment of Low-Temperature Plasma Technologies for Treating Volatile Organic Compound Emissions from Pulp Mills and Wood Products Plants”. The heterogeneous pulsed corona discharge was chosen as the best non-equilibrium plasma technology for control of the vent emissions from HVLC Brownstock Washers. The technology for removal of Volatile Organic Compounds (VOCs) from gas emissions with conditions typical of the exhausts of the paper industry by means of pulsed corona plasma techniques presented in this work. For the compounds of interest in this study (methanol, acetone, dimethyl sulfide and $\alpha$-pinene), high removal efficiencies were obtained with power levels competitive with the present technologies for the VOCs removal. Laboratory experiments were made using installation with the average power up to $20 \mathrm{~W}$. Pilot plant prepared for on-site test has average plasma power up to $6.4 \mathrm{~kW}$. The model of the Pilot Plant operation is presented.
\end{abstract}

\section{INTRODUCTION}

Volatile Organic Compounds are a class of air pollutants that has been addressed by environmental regulations in the past few decades, due to their toxicity and their contribution to the global warming mechanism. In the paper industry, they are mainly contained into solvents, chemical binders, bleaching chemicals for paper production; they are also contained into the wood itself and they are released into the exhaust gases during the processing of the wood paste.

The target of this work is the reduction of the VOCs contained in the vent streams from brownstock washers of paper production plants. These emissions produce low VOC concentrations and are classified as high volume -low concentration (HVLC) gas streams. Average composition and conditions of this stream are presented in Table 1. Major traditional techniques for VOC removal include biological filters, two stage adsorbers and, most important, regenerative thermal incineration or regenerative thermal oxidation (RTO). These methods for the treatment of the dilute off-gases require relatively high energy consumption and result in high treatment costs [1].

\section{TABLE 1. ESTIMATED GAS COMPOSITION AND PROCESS CONDITIONS FOR BROWNSTOCK WASHER WENT STREAM}

\begin{tabular}{|c|c|}
\hline Methanol & $83 \mathrm{ppm}$ \\
\hline Acetone & $3 \mathrm{ppm}$ \\
\hline $\boldsymbol{\alpha}$-Pinene & $209 \mathrm{ppm}$ \\
\hline Dimethyl Sulfide & $2 \mathrm{ppm}$ \\
\hline Humidity & $100 \% \mathrm{RH}$ \\
\hline Temperature & $110^{\circ} \mathrm{F}$ \\
\hline
\end{tabular}

Gas phase hazardous organic wastes can be destroyed by oxidation to non-hazardous compounds, such as carbon dioxide and water. The most effective way of oxidizing organics is to use highly reactive species, i.e. reactants with a high oxidizing potential, such as $\cdot \mathrm{OH}, \cdot \mathrm{O}, \cdot \mathrm{H}, \mathrm{O}_{3}$, and $\mathrm{H}_{2} \mathrm{O}_{2}$. The hydroxyl radical is especially known to play an important role in oxidative purification and degradation of organic compounds [2]. 
In a combustion process, efficiency of production and concentration of these free radicals and active species depend on the reaction temperature. In order to attain the required temperature, a considerable amount of energy must be spent for direct heating of the gas (e.g., by incineration or thermal plasma). To perform incineration of HVLC gas streams, some quantity of fuel must be added to promote effective combustion, since the concentration of organic material is not sufficient to sustain combustion by itself. To uniformly heat the whole gas stream by thermal arc, a high amount of electric energy must be spent. Both these methods are inefficient in terms of production of active species [3].

Low-temperature non-equilibrium (non-thermal) plasma discharges represent an alternative technology for gas phase de-pollution. Here most of the energy (up to 99.9\%) is directed in the production of high-energy electrons [4], rather than in heating the gas. Radicals, ions and other active species, which oxidize, reduce or decompose the pollutant molecules, are efficiently produced mainly via electron-impact dissociation, excitation and ionization of the background gas. Non-equilibrium discharges have been tested for the removal of a number of different toxic or environmentally hazardous compounds, such as $\mathrm{SO}_{x}, \mathrm{H}_{2} \mathrm{~S}$, VOCs, PAHs (Polycyclic Aromatic Hydrocarbons), heavy metals, and others, like chemical warfare gases such as nerve gas [5-11]. Gliding arc and pulsed corona were used as non-thermal plasma sources. Gliding arc applications to plasma chemistry processes have been tested experimentally and demonstrated in industrial scale plants. Corona discharge application also has been proposed for removal of VOCs from liquid [2] and gas phase [12]. Both discharges generate non-equilibrium plasma, but they differ in the physical characteristics and in the level of power consumption.

Under the DOE Office of Industrial Technologies Forest Products program various plasma technologies were evaluated under project FWP 49885 "Experimental Assessment of Low-Temperature Plasma Technologies for Treating Volatile Organic Compound Emissions from Pulp Mills and Wood Products Plants". The objective of this project was to test four candidate VOC control technologies based on non-thermal plasma, and demonstrate the best technology in a mill. Previous work sponsored by NCASI reviewed the feasibility of non-thermal plasmas for VOC control application in the forest products industry [18]. In that work, published data from all non-thermal processes being currently developed were reviewed to estimate the applicability of the process to contaminants and conditions typical for forest products applications. Four non-thermal plasma technologies appeared to promise both lower capital costs and operating costs than the incineration-type process currently available. They are: 1) dielectric packed bed corona discharge (GCPR); 2) electron beam discharge; 3) non-thermal gliding arc discharge; and 4) heterogeneous pulsed corona discharge. After the tests the heterogeneous pulsed corona discharge [19] was chosen as the best non-equilibrium plasma technology for control of the vent emissions from HVLC Brownstock Washers.

The corona discharge was generated by applying a negative pulsed voltage to a wire into-cylinder system. The advantage of this system with respect to the DC corona is that, applying the voltage as fast rising pulses it is possible to obtain high-energy electrons even with small power. The electron energy, in fact, depends on both the intensity of the electric field (i.e. on the voltage) and the mean time of collision of electrons with other molecules. For a fast rising pulse, the mean electric field when in the pulse is very high (since the peak voltage is high), allowing the electrons to gain enough energy for the discharge to take place; however, since the duration of each pulse is much smaller than the time lag between pulses, the mean required power is low (e.g. it is in the order of few Watts for the setups used for laboratory experiments) even though the actual power of each single pulse is very high (on the level of $1 \mathrm{MW})$.

Heterogeneous plasma systems, containing both a non-equilibrium gas discharge and a liquid phase, were also developed and appear to be promising for industrial application both in terms of VOC removal efficiency and power consumption. In these systems, in fact, those VOCs that are soluble in water and other byproducts from the plasma treatment are removed from the gas stream with virtually no cost (if water is already present in the industrial operations); the power requirements are then reduced, since only a smaller amount of pollutants needs to be removed by plasma induced oxidation. After partial oxidation of non-soluble VOCs most of by-products become soluble and is absorbed by water also. This results in additional power reduction. The application of the heterogeneous systems appears to be practical in those industries, such as the wood product industry, that already implemented control and purification technologies on the liquid effluents from the work processes. When after the laboratory tests the heterogeneous pulsed corona discharge was chosen as the best non-equilibrium plasma technology for control of the vent emissions from HVLC Brownstock Washers, DOE and the project partners have provided funding for the pilot plant development and test in the frame of the continuation of the 
project. The trailored pilot plant with heterogeneous pulsed corona of $8 \mathrm{~kW}$ average discharge power was developed and is ready for testing in industrial conditions.

\section{LABORATORY EXPERIMENTAL SETUP AND APPROACH}

\section{Pulsed Corona Discharge Experimental Setup}

Two different types of corona setup were used for the experiments: a "dry" (or "regular") corona and a "wet" corona discharge; the wet corona setup allows for a water film to flow on the internal walls of the reactor. Both the corona discharges were generated in a wire-into-cylinder coaxial electrode system. A schematic of the wet corona reactor is presented in Figure 1. Schematic of the "dry" corona was similar in general. For the "dry" corona setup the inner, high voltage electrode is a $0.5 \mathrm{~mm}$ diameter Inconel ${ }^{\mathbb{B}}$ wire. The Inconel ${ }^{\circledR}$ alloy has been selected for its superior heat and oxidation resistance. The outer electrode is a $1.2 \mathrm{~m}$ long cylindrical stainless steel tube with a $22.2 \mathrm{~mm}$ internal diameter. The inner surface is polished to avoid localized enhancements of the electric field due to roughness of the electrode and to provide a uniformly distributed discharge. It is placed inside a tubular high temperature furnace; the central, high-temperature section of the reactor is $0.9 \mathrm{~m}$ long; the low-temperature lateral sections of the reactor are used for electrical and gas connections. The tubular furnace (model 3200, Lindberg Inc.), can be stabilized at a temperature as high as $1200^{\circ} \mathrm{C}$, with accuracy better than $20^{\circ} \mathrm{C}$. For these experiments, temperature was varied between 70 and $220^{\circ} \mathrm{C}$. The inner wire is held and centered by means of two Teflon ${ }^{\circledR}$ holders, located at both the ends of the external electrode. These pieces serve for hermetic sealing and for insulation of the discharge region. In order to preheat the gas, the stainless steel tube of the supply line is also placed inside the tubular furnace. K-type thermocouples are attached to both inlet and outlet connections of the reactor, with the purpose of providing temperature data.

For the wet-type corona (Fig. 1), the external electrode is made up of a $60 \mathrm{~cm}$ long cylindrical glass tube with a 22.2 $\mathrm{mm}$ internal diameter, surrounded by a sheet of perforated metal. The internal wall of the glass tube is covered by a layer of absorbing material, which forms a uniformly distributed water film in the reactor. The wet reactor is not heated; with this specific setup all the experiments were performed at room temperature. The tube is held at the top by a Teflon holder and at the bottom by a stainless steel holder; stainless steel was chosen for the bottom of the reactor to prevent deterioration of the holder itself due to the byproducts expected in the liquid phase, such as sulfuric acid. The reactor is sealed by means of silicon rubber o-rings. The top holder contains the connections of the lines for the incoming water and the outgoing gas; water is introduced into the reactor through sixteen, equally spaced holes with a diameter of ${ }^{1} / 32 "(\sim 0.8 \mathrm{~mm})$, to guarantee a uniform injection around the circular tube. It also contains the connection for the internal, high voltage electrode and for the high voltage probe. The bottom holder includes threaded holes for the gas inlet and for the water outlet. In order to avoid any contact between this metal holder and the HV electrode and to prevent the formation of sparks, the wire is fixed to the holder through a Teflon insert, which completely contains the lower portion of the wire.

\section{Supply and Diagnostics Systems}

An overall schematic of the experimental setup is shown in Figure 2. In this figure the schematic is shown with the gliding arc system that was also used in this type of tests (see the Introduction chapter). Typical VOC compositions of tested streams were simulated in the laboratory by blending a combination of gaseous and liquid species to generate industrial-like streams. Inlet gas flow rate was metered by mass flow controllers. The air for the experiments is provided by a dry air supply, that ensures the removal of residuals of water and organic compounds, which could be present in the air line. Liquid flows of water and VOCs were supplied to the system by two HPLC Pumps (models I and II, LabAlliance Inc.) with an operating range from 0.1 to $10 \mathrm{ml} / \mathrm{min}$ and $2 \%$ accuracy. The pumps use step motor driven pistons, ensuring good accuracy and repeatability. In the wet corona reactor, the flow of the water film was precisely metered by using one of the HPLC pumps, for flow rates up to $10 \mathrm{ml} / \mathrm{min}$; when higher flow rate was required, two Brooks flow-meters were used.

In order to evaporate the liquid components and to properly mix the different chemicals, a stainless steel mixing chamber, heated up to $160^{\circ} \mathrm{C}$ and filled with glass beads, was placed before the reactors. All stainless steel connecting lines were heated by means of heating tapes to prevent condensation of reactants and products. The developed supply system provides reliable control on the chemical composition of the process streams and allows for varying of VOC concentration in a fairly wide range. 


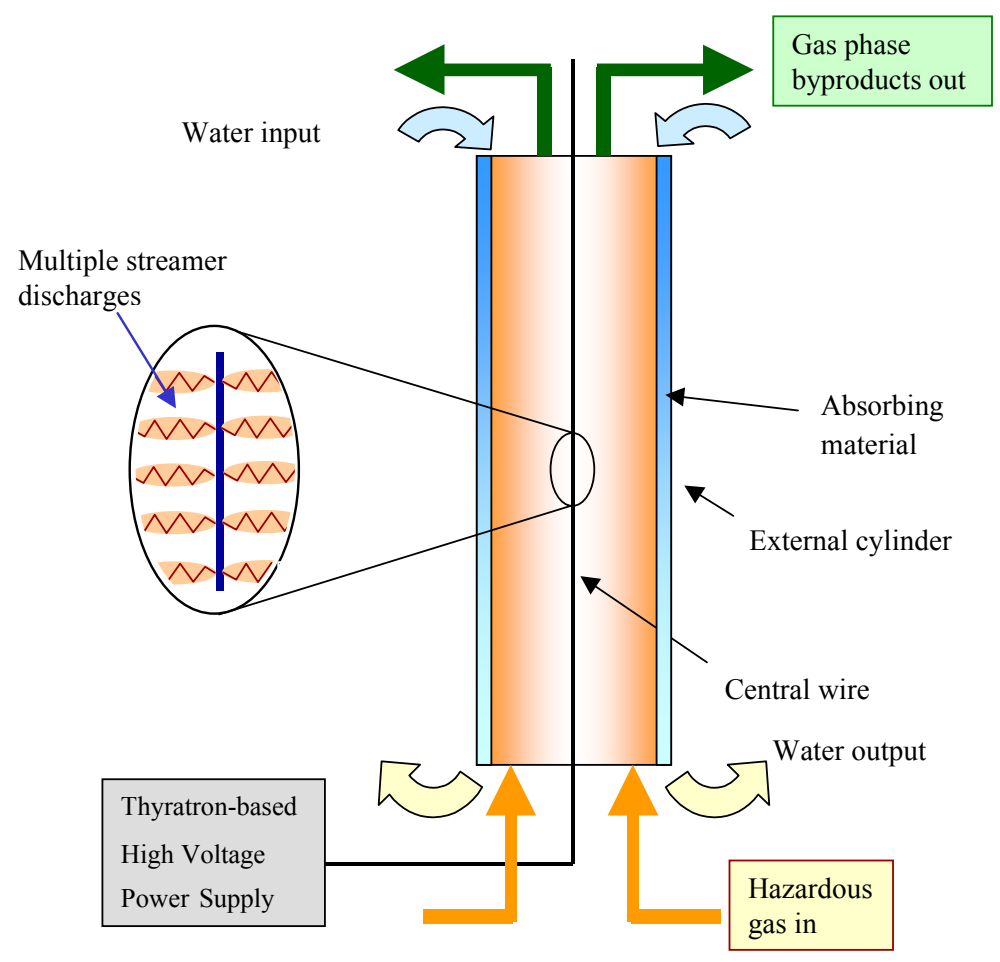

Figure 1. Schematic of the wet corona reactor

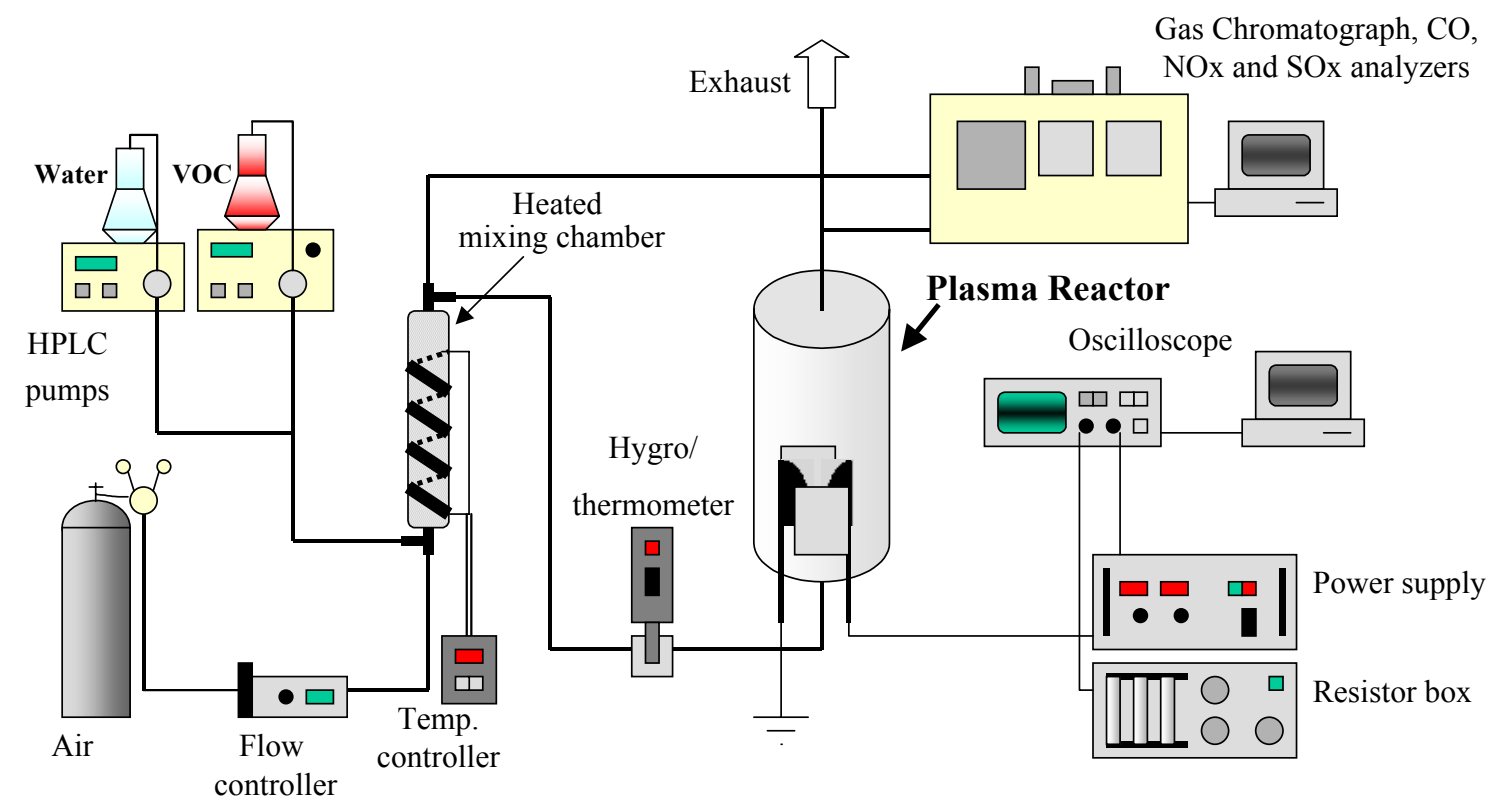

Figure 2. Schematic of the experimental setup 
Chemical and electrical diagnostic systems were used. Gas composition was determined by Gas Chromatograph (Varian Inc, Model 3600), analyzing input and output samples. For the sampling, a part of the gas stream from the reactors was directed to the GC, collected in a $0.25 \mathrm{ml}$ gas-sampling loop, injected into the capillary column (Supelcowax-10) by means of compressed air operated valves, and analyzed with a Flame Ionization Detector (FID). A specific GC method was developed, in order to process the results by the Star Chromatography Workstation (Version 5.31).

$\mathrm{CO}$ and $\mathrm{SO}_{\mathrm{x}}$ were measured by infrared analyzers (Beckman Industrial 867 and Horiba Via-510, respectively) and $\mathrm{NO}_{\mathrm{x}}$ evaluation was done by a chemiluminescence analyzer (Thermoenvironmental Instrument $42 \mathrm{H}$ ). Certified gas mixtures were used for the calibration of all the analyzers.

Electrical characteristics were acquired with a digital oscilloscope (HP 546126B). The digitized waveforms were then transmitted to a computer and analyzed with the HP 34801A-BenchLink Scope software.

\section{RESULTS AND DISCUSSION OF BENCH-TOP EXPERIMENTS}

The use of non-equilibrium plasma for pollution reduction has already been proposed and tested on a variety of pollutants. In order to show the possibility of applying this technology for the removal of the specific chemical compounds of interest in this project, a completely non-equilibrium discharge, such as the pulsed corona discharge, has been chosen.

\section{$\underline{\text { Regular Pulsed Corona Discharge - Experimental Results }}$}

The application of pulsed corona discharge for VOC removal was investigated. Experimental parameters varied during the tests include the humidity of the gas, the temperature of the corona reactor, the frequency of the corona discharge, the composition of the gas to treat, and, for the wet corona, the water flow rate of the liquid film. Tests were performed both with the complete mixture of chemicals, including methanol, acetone, alpha-pinene and dimethyl sulfide, and with the single compounds.

Experiments were conducted using both wet and regular corona discharges. Given the different length of the reactors, respectively 23" and 46" for the wet and regular type corona reactors, the gas flow was controlled to have equal residence time; the gas flow rate through the regular corona reactor was 2 SLM, and 1 SLM through the wet corona reactor, resulting in a residence time of about 13 seconds.

Decomposition of each compound was the object of a series of experiments using the regular corona discharge. The experimental conditions for this type of tests are shown in Table 2. The brownstock washer vent emission was the industrial stream target of these experiments. Concentration was considered as the main parameter. It was varied within a fairly large range. It allows for reaching a better understanding of the actual destruction and removal efficiency and of the production of byproducts for each single compound. Using this approach, the other gas streams of interest in this work, such as the oriented strandboard press vent emission and the oriented strandboard dryer vent emission, are also studied.

\section{TABLE 2. EXPERIMENTAL CONDITIONS}

\begin{tabular}{|r|c|c||}
\hline GAS & BROWNSTOCK & STUDIED \\
COMPOSITIONS & WASHER VENT EMISSIONS & EXPERIMENTAL CONDITIONS \\
\hline \hline Methanol & $83 \mathrm{ppm}$ & from $5 \mathrm{ppm}$ to $1000 \mathrm{ppm}$ \\
\hline Acetone & $3 \mathrm{ppm}$ & from $5 \mathrm{ppm}$ to $1000 \mathrm{ppm}$ \\
\hline Terpenes & $209 \mathrm{ppm}$ & from 150 to $800 \mathrm{ppm}$ \\
\hline Dimethyl Sulfide & $20 \mathrm{ppm}$ & from $5 \mathrm{ppm}$ to $1000 \mathrm{ppm}$ \\
\hline \hline \multicolumn{2}{|c|}{ PROCESS CONDITIONS } \\
\hline Humidity & $100 \% \mathrm{RH}$ & from $0 \%$ to $100 \%$ \\
\hline Temperature & $45^{\circ} \mathrm{C}$ & from room temperature to $220^{\circ} \mathrm{C}$ \\
\hline
\end{tabular}


Main figures of merit in the study of the removal of VOCs are the destruction and removal efficiency (DRE), defined as the percentage by mole of organic compounds removed with respect to the initial amount of the same VOC, and the Specific Energy Input, which represents the energy consumed per unit volume of gas treated.

\section{Removal of Acetone and Methanol by Pulsed Corona Discharge}

The concentration of both acetone and methanol were varied between $5 \mathrm{ppm}$ and $1000 \mathrm{ppm}$ in the experimental analysis. Corona frequency was varied between $266 \mathrm{~Hz}$ and $1450 \mathrm{~Hz}$, to study the effect of different values of electric power on the removal of acetone. Temperature of the corona reactor was kept constant at $200^{\circ} \mathrm{C}$. Water was introduced, at a flow rate equal to $0.25 \mathrm{ml} / \mathrm{min}$, and completely vaporized. The humidity level corresponds to saturation at about $55^{\circ} \mathrm{C}$; the same level of relative humidity is used also in all the other experiments, when water vapor is introduced. In Figure 3, DRE values for different initial concentrations of acetone and electric power consumption are plotted as functions of corona frequency.

Power consumption varies considerably as a function of corona frequency. It also varies, but less significantly, with the VOC concentration in the gas stream. It actually increases with increasing the concentration of organic compounds. The power consumption presented in Figure 3 is an average value of the power consumed for the four different concentrations of acetone analyzed in the experiments; it shows a fairly linear dependence with respect to the frequency. This is due to the electric characteristics of the voltage pulses supplied: the pulse rise time and the pulse period are very short (respectively $10 \mathrm{~ns}$ and $100 \mathrm{~ns}$ ) compared to the pulse frequency, that is as high as 1.45 $\mathrm{kHz}$ in these experiments; even when working with the highest corona frequency, the interpulse interval is about 7000 times longer than the pulse duration itself. Because of this large interval, the presence of a pulse does not significantly influence the shape of the following pulses and all the pulses have the same waveform. The current and voltage waveforms of the pulse itself depend on the peak voltage value. With increase of the peak voltage, higher current is supplied to the discharge and the power load is higher. If the value of the peak voltage is kept constant, i.e. if the energy of each single pulse is constant, then the power consumption depends almost linearly on the frequency of the pulses. This behavior of the power curve can also be observed for the other experiments in this work, since it mainly depends on the characteristic of the pulse voltage power supply. The slight non-linearity of power with respect to frequency is due to the fact that the power depends also on the composition of the gas where the discharge occurs. For constant peak voltage it can be observed that the power consumption varies for different acetone concentrations: it actually increases for higher concentration of organic material in the gas stream. For the tests with $1000 \mathrm{ppm}$ of acetone, the power consumption is lower due to the lower value set for the peak voltage (11 $\mathrm{kV}$, instead of $12 \mathrm{kV}$ as for the others experimental runs).

It is evident that the DRE of acetone depends strongly on the initial composition of the inlet gas and on the corona frequency, i.e. on the power of the corona discharge. For higher power levels, higher values of DRE can be reached. Increasing the concentration of acetone in the gas stream, the electric power supplied to the discharge must increase in order to reach the same value of DRE.

The outlet gases from the plasma reactor were also tested for organic byproducts of acetone destruction. No organic byproducts were detected for gas streams with initial acetone concentrations equal to $5 \mathrm{ppm}$ and $20 \mathrm{ppm}$. For the gas stream containing $200 \mathrm{ppm}$ and $1000 \mathrm{ppm}$ of acetone, methanol was detected, in very small concentrations, as shown in Table 3.

TABLE 3. METHANOL CONCENTRATION [PPM] AS BYPRODUCT OF ACETONE DESTRUCTION IN THE REGULAR CORONA DISCHARGE

\begin{tabular}{|c|c|c|c|c|}
\hline \multirow{2}{*}{$\begin{array}{c}\text { Corona Frequency } \\
{[\mathbf{H z}]}\end{array}$} & \multicolumn{4}{|c|}{ Initial Concentration of Acetone } \\
\cline { 2 - 5 } & $\mathbf{5}$ & $\mathbf{2 0}$ & $\mathbf{2 0 0}$ & $\mathbf{1 0 0 0}$ \\
\hline \hline $\mathbf{2 6 6}$ & 0 & 0 & $<1$ & $\approx 3$ \\
\hline $\mathbf{6 6 7}$ & 0 & 0 & $<1$ & $\approx 5$ \\
\hline $\mathbf{1 4 5 0}$ & 0 & 0 & $\approx 2$ & $\approx 7$ \\
\hline
\end{tabular}




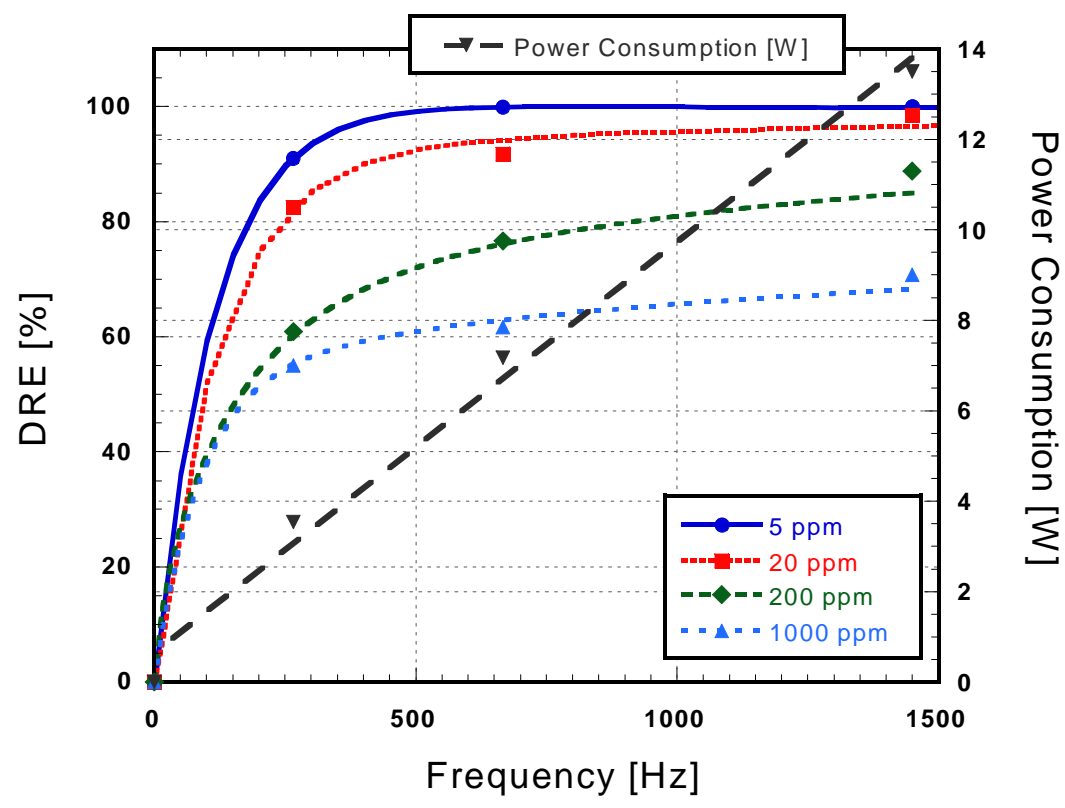

Figure 3. DRE and electric power consumption as a function of the corona frequency for treatment of acetone in regular corona discharge.

Methanol removal in the pulsed corona discharge was also studied. Even though the concentrations of methanol targeted in this work are those presented in Table 1, also for methanol some experiments were run at higher concentration. In industrial operations, however, the concentrations in the streams can vary significantly; methanol concentration can be as high as $2300 \mathrm{ppm}$ in a worst-case scenario.

Figure 4 shows DRE and the average electrical power consumption obtained from a series of experiments conducted at $200^{\circ} \mathrm{C}$. For all experiments with methanol, the peak pulse voltage has been kept constant to $11 \mathrm{kV}$. The dependence of the power consumption on the concentration of organics in the gas flow to treat is then more evident in this case than in the experiments with acetone. For a fixed value of pulse frequency, more power is consumed for higher VOC concentrations, as it is shown in Figure 5.

Chromatographic data shows that no organic byproducts are produced from the destruction of methanol. It is due to the fact that methanol is already a partially oxidized molecule and further oxidation can easily produce non-organic compounds. This result, together with the low $\mathrm{CO}$ levels detected (in the levels of $0.1 \mathrm{ppm}$ ), means that the organic carbon contained in the methanol molecule is completely oxidized to $\mathrm{CO}_{2}$.

The efficiency of the decomposition process is limited by the reaction rate of the VOCs with the plasma-produced radicals and/or by the occurrence of back reactions. Data on the gas temperature dependence provides a good basis for elucidating the chemical kinetics of methanol destruction. The dependence on temperature was studied varying the temperature of the corona reactor between $70^{\circ} \mathrm{C}$ and $220^{\circ} \mathrm{C}$, for a gas flow containing about $200 \mathrm{ppm}$ of methanol and with a constant corona frequency equal to $667 \mathrm{~Hz}$. An example of results from the $\mathrm{GC}$ is presented in Figure 6. These chromatograms are obtained from a series of experiments where the only variable is the temperature of the corona reactor, while all the other parameters that could influence the DRE (initial VOC concentration, peak voltage, pulse frequency, and humidity level) are kept constant. It is clear from this figure that the methanol removal efficiency depends dramatically on the temperature of the reactor: the area of the peaks, that is proportional to the amount of methanol in the gas sample, shrinks with increasing temperature. This shows that the concentration of methanol present in the exhaust gases after the plasma processing decreases significantly with increasing temperature. The resulting data on DRE and SEI are presented in Figure 7.

Two main reasons can explain the reduction in the efficiency of methanol destruction at lower temperature: the different kinetics of the reactions of methanol with the active species produced by plasma and the decrease of the 
SEI. It is interesting to observe that even though the pulse frequency is kept constant, the power delivered to the discharge varies as an effect of the reactor temperature. Decreasing the temperature of the corona reactor causes two effects: it slows down the chemical kinetics of the reactions of methanol oxidation and reduces the power load. Both these effects contribute to the lower the destruction efficiency of methanol.

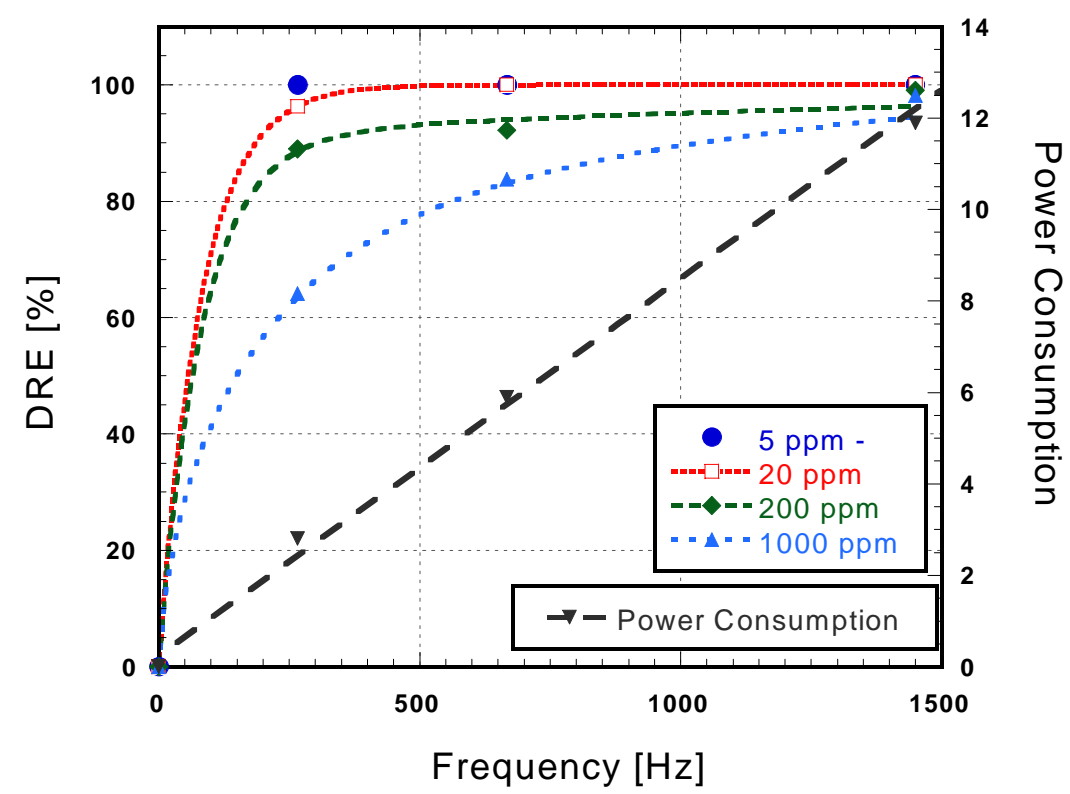

Figure 4. DRE and electric power consumption as a function of the corona frequency for treatment of methanol in regular corona

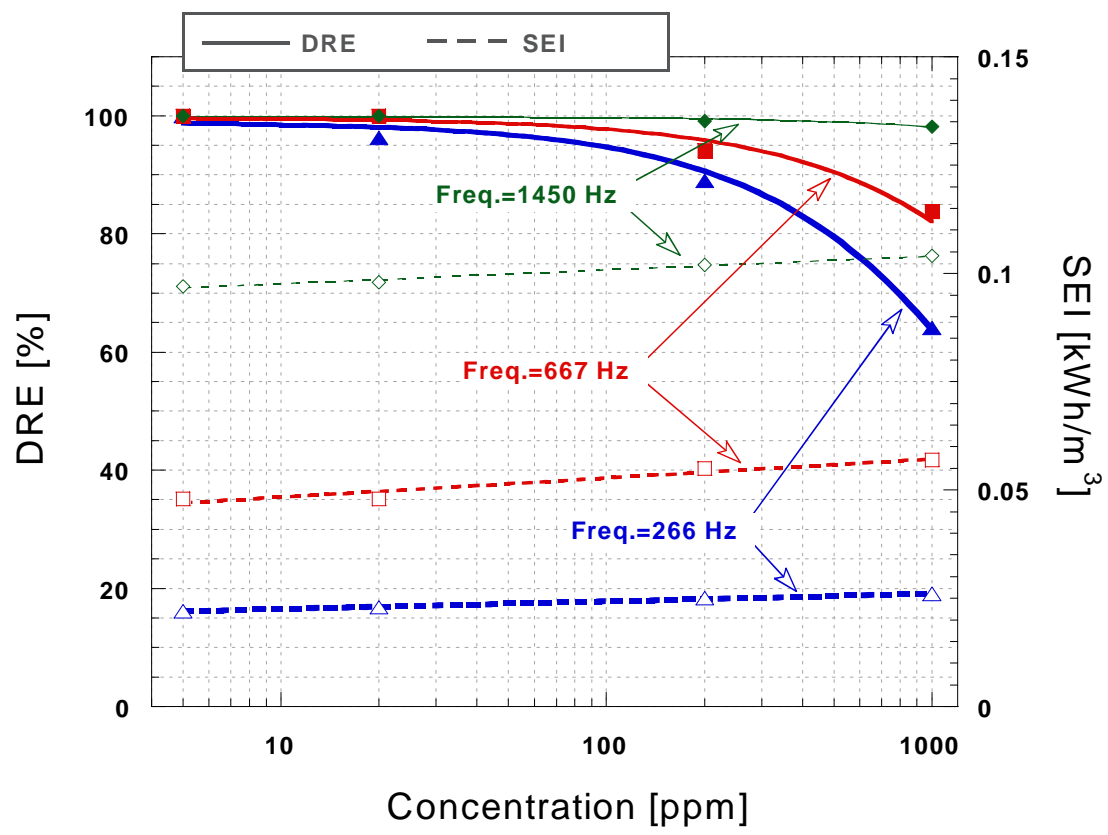

Figure 5. DRE and SEI as function of the initial methanol concentration. 


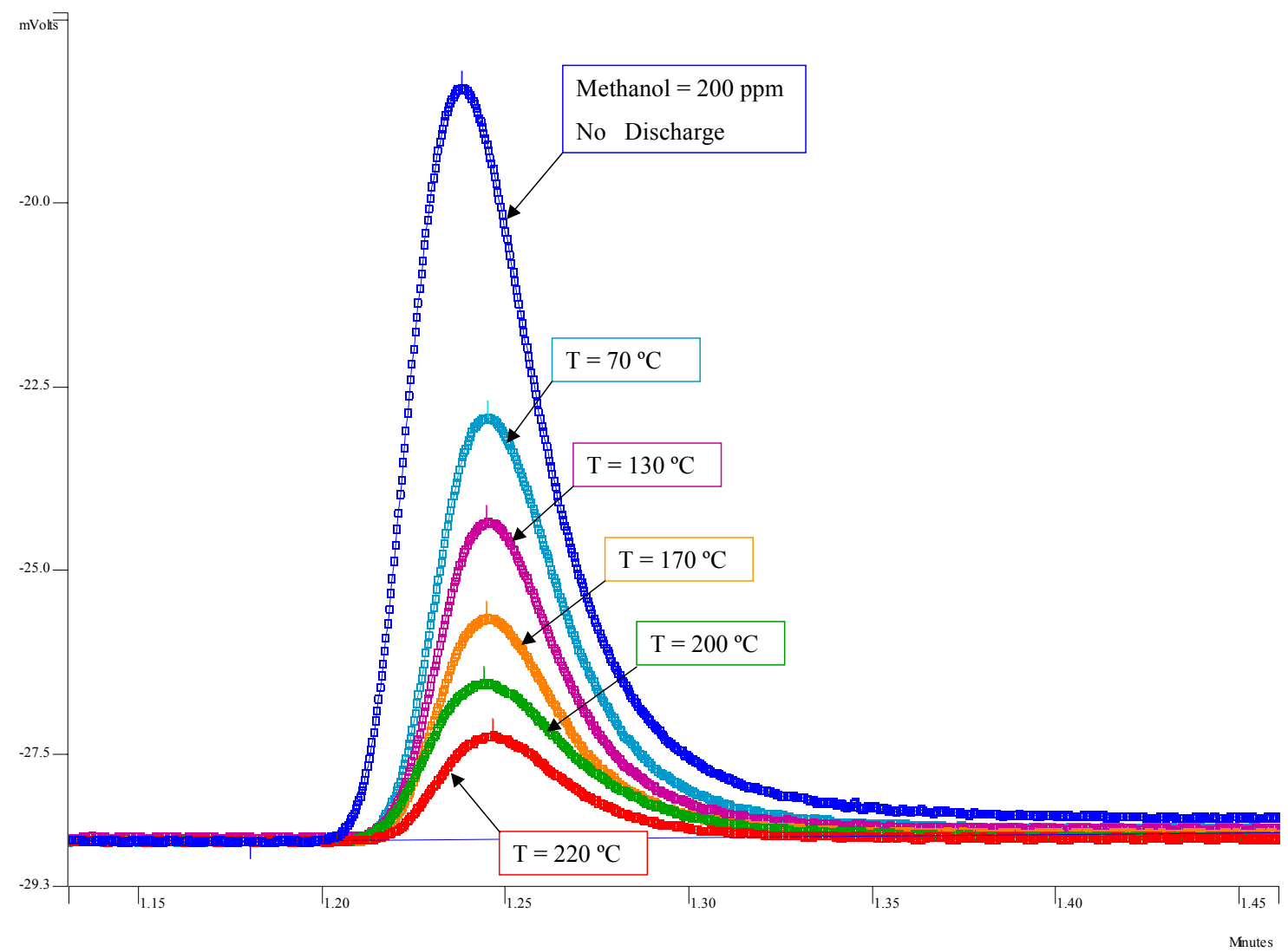

Figure 6. Representative Gas Chromatograms, showing the methanol peaks after treatment in the corona reactor as a function of temperature.

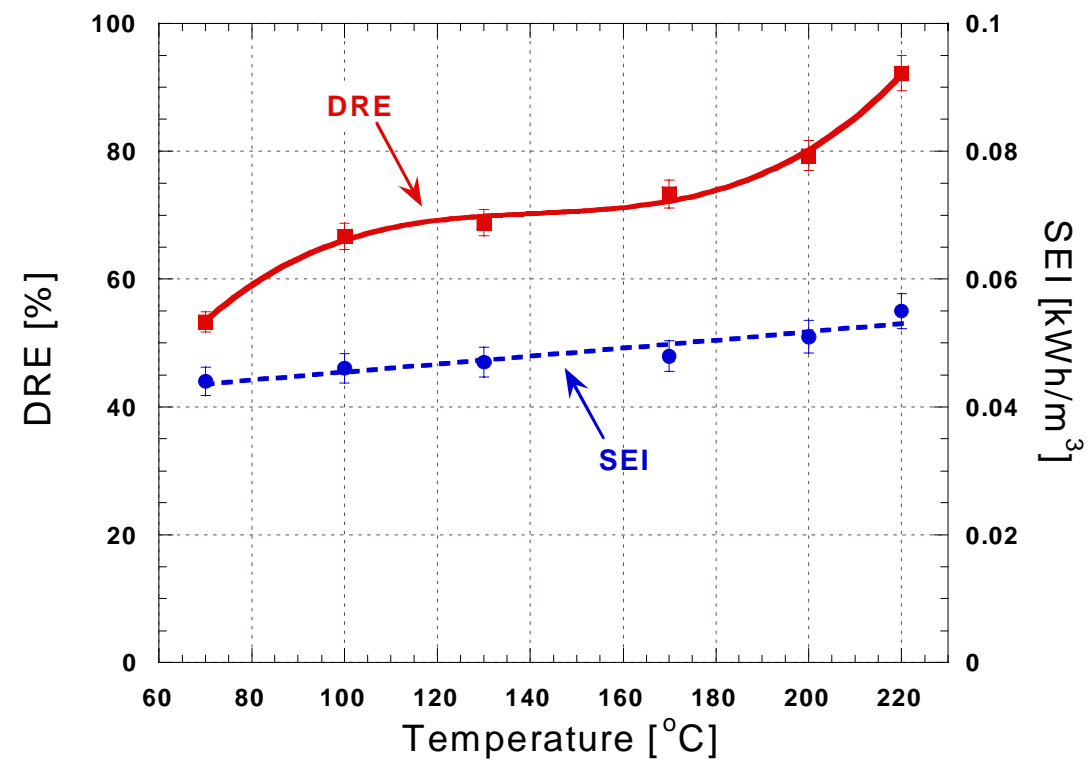

Figure 7. DRE and SEI as a function of temperature removal 200 ppm of methanol. 
This data is also interesting from the standpoint of the industrial application, both because the three target gas streams are characterized by temperatures in the range from $50^{\circ} \mathrm{C}$ to $100^{\circ} \mathrm{C}$ (or even higher), and because the actual process conditions for each single stream are subject to variations.

A figure of merit for the VOC destruction is the Energy Price, $\chi$, i.e. the energy delivered to the plasma per hazardous molecule removed from the gas stream. Convenient units for this parameter are the number of kilowatthours required to remove a kilogram of hazardous compound (as proposed by Rosocha et al. [3]) or the electronvolts per VOC molecule. The Energy Price provides a normalized value of the energy consumption with respect to the actual quantity of chemical destroyed. Energy Price values decrease from $290 \mathrm{kWh} / \mathrm{kg}$ to $200 \mathrm{kWh} / \mathrm{kg}$ when temperature is increased from $70^{\circ} \mathrm{C}$ to $220^{\circ} \mathrm{C}$. It means that, as temperature decreases, the reduction of the destruction rate is predominantly due to the effect of the slower kinetics: in fact, with reducing temperature, the power consumption in the corona discharge decreases, while the value of $\chi$ increases, even though $\chi$ is proportional to the corona power.

From the standpoint of the industrial application of this work, the objective is obtaining a reduction of at least $98 \%$ of the VOC contained in the gas streams. These results show that this objective is fully accomplished for treating a gas flow with acetone concentration comparable to the brownstock washer vent emissions, where acetone concentration is actually lower than $5 \mathrm{ppm}$. Also for the gas streams with acetone concentration comparable to the oriented strandboard dryer vent emissions, acetone removal efficiency equal to $98 \%$ can be reached for a reasonably low energy input $\left(\mathrm{SEI} \approx 0.08 \mathrm{kWh} / \mathrm{m}^{3}\right)$.

Methanol seems to be a compound that decomposes fairly easily, in a corona discharge, with low energy consumption levels. The objective of $98 \%$ destruction can be reached for all analyzed gas compositions. Projection of these results to a concentration of about $2300 \mathrm{ppm}$, i.e. considering the worst-case scenario for methanol content in the brownstock washer vent emissions, shows that a significant amount of energy (probably on the level of 0.5 $\mathrm{kWh}$ per cubic meter of gas or higher) must be supplied in order to reach this high degree of gas purification.

\section{Removal of Dimethyl Sulfide by Pulsed Corona Discharge}

A gas stream containing only dimethyl sulfide (DMS) was tested, for concentrations up to $1000 \mathrm{ppm}$. From the industrial point of view, dimethyl sulfide $\left(\mathrm{C}_{2} \mathrm{H}_{6} \mathrm{~S}\right)$ is the volatile organic compound of main concern: dimethyl sulfide is highly toxic, flammable and emanates a foul odor; the odor threshold is on the level of $1 \mathrm{ppb}$. In an industrial worst case scenario, DMS concentration can be as high as $1700 \mathrm{ppm}$, but such a high concentration has been avoided in the experiments due to laboratory safety reasons, considering its high flammability. Temperature of the corona reactor was kept constant at $220^{\circ} \mathrm{C}$; the peak voltage was kept equal to $12 \mathrm{kV}$.

DRE is presented in Figure 8 as a function of the specific energy input. Dimethyl sulfide appears to be extremely easy to decompose even for fairly high concentrations: for an initial concentration up to $200 \mathrm{ppm}$, no dimethyl sulfide is detected by the Gas Chromatograph in the after-treatment gases. For these concentration levels, the smallest power supplied to the discharge is sufficient to completely oxidize this VOC. Also for higher concentrations, the target DRE of at least $98 \%$ can be reached with fairly low Specific Energy Input; SEI is on the level of $0.05 \mathrm{kWh} / \mathrm{m}^{3}$ for the gas stream with the highest concentration of dimethyl sulfide considered. By plotting the DRE as a function of the SEI, a negative exponential behavior is observed. The same kind of behavior occurs also for the removal of acetone and methanol, as it was shown in Figure 3 and Figure 4 with respect to frequency, on which power consumption and SEI depend linearly.

The presence of byproducts from the oxidation of dimethyl sulfide was also tested, showing that traces of organic compounds are contained in the exhaust gas. The only organic byproduct identified in the exhaust gases is methanol. Detected methanol concentrations, shown in Table 4, depend on the initial concentration of dimethyl sulfide and on the power supplied to the discharge. Dimethyl sulfide appears to be preferentially oxidized over methanol by the active species produced by the discharge. From the experiments with an initial concentration of $200 \mathrm{ppm}$ and $400 \mathrm{ppm}$ and the lowest power supplied, in fact, it is evident that while all the DMS is removed, methanol is still present in the outlet gas. Only by increasing power, is methanol also oxidized, so that its concentration in the exhaust gas decreases. For an initial concentration equal to $1000 \mathrm{ppm}$, DMS is not completely 
removed; for this initial concentration, when increasing the power input, the amount of methanol increases, due to the fact that a bigger fraction of dimethyl sulfide, but not all of it, is oxidized.

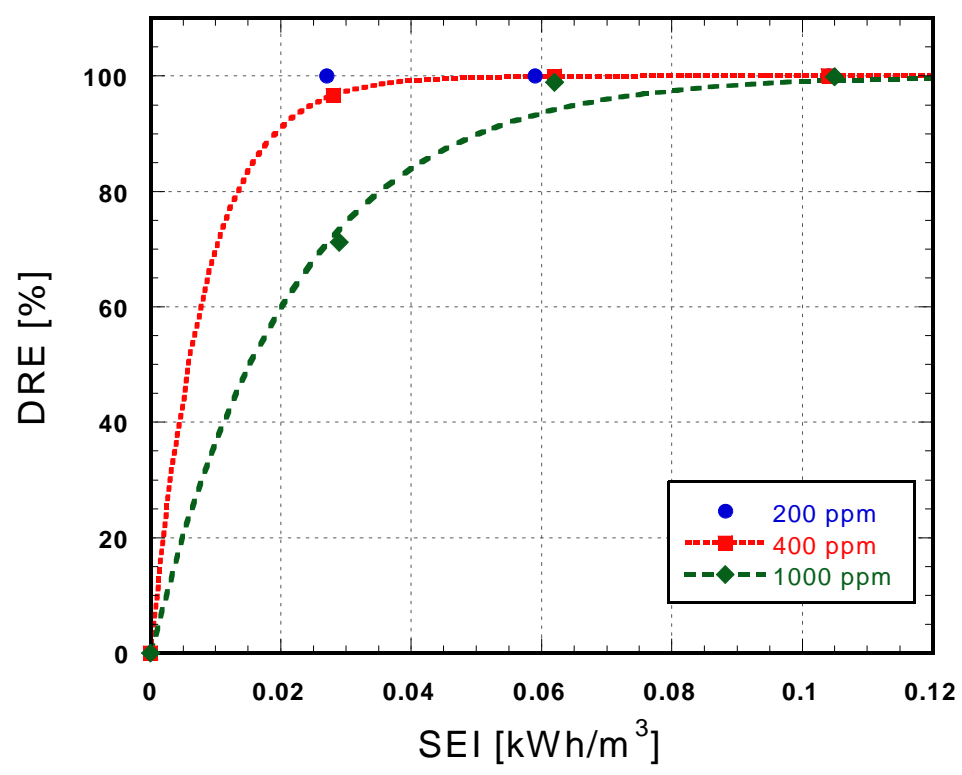

Figure 8. DRE as a function of the SEI for treatment of dimethyl sulfide in regular corona

Table 4. Methanol concentration [ppm] as byproduct of the destruction of dimethyl sulfide in the regular corona discharge.

\begin{tabular}{|c|c|c|c|c|c|c|}
\hline \multirow{2}{*}{$\begin{array}{c}\text { Frequency } \\
{[\mathrm{Hz}]}\end{array}$} & \multicolumn{5}{|c|}{ Initial Concentration of Dimethyl Sulfide [ppm] } & \multirow{2}{*}{$\begin{array}{l}\text { Mean SEI } \\
{\left[\mathrm{KWh} / \mathbf{m}^{3}\right.}\end{array}$} \\
\hline & 5 & 20 & 200 & 400 & 1000 & \\
\hline 256 & 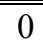 & 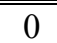 & $\bar{~} \sim 5$ & 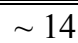 & $2 \sim 21$ & 0.027 \\
\hline 667 & 0 & 0 & $\sim 4$ & $\sim 12$ & $\sim 28$ & 0.06 \\
\hline 1450 & 0 & 0 & $\sim 2$ & $\sim 8$ & $\sim 37$ & 0.103 \\
\hline
\end{tabular}

Oxidation of dimethyl sulfide is the subject of a number of studies on atmospheric chemistry since it is one of the primary organo-sulfur compounds emitted to the atmosphere. Mechanisms of DMS oxidation are complex and can involve different active species produced by the plasma discharge. The pulse corona discharge in presence of water involves a complex sequence of chemical reactions. The main reactions are assumed to produce $\cdot \mathrm{OH}$ and $\mathrm{H}_{2} \mathrm{O}_{2}$ [13]. Other active species (such as atomic oxygen, atomic nitrogen or ozone) are also produced, mainly by the interaction of the energetic electrons with oxygen and nitrogen molecules. Among these active species, the hydroxyl radical, especially, is known to play an important role in initiating the oxidation of organic compounds, given that $\cdot \mathrm{OH}$ has the highest value of oxidation potential. Chemical mechanisms of oxidation of DMS are found in the literature $[14,15]$. They show that, at $298 \mathrm{~K}$, organic sulfur-containing byproducts are produced, even though $\mathrm{SO}_{2}$ remains, under most conditions, the main final oxidation product.

The reaction of $\cdot \mathrm{OH}$ with dimethyl sulfide can proceed via several channels:

$$
\begin{aligned}
& \mathrm{OH}+\mathrm{CH}_{3} \mathrm{SCH}_{3}(+\mathrm{M}) \leftrightarrow \mathrm{OH} \cdot \mathrm{CH}_{3} \mathrm{SCH}_{3}(+\mathrm{M}) \\
& \mathrm{OH}+\mathrm{CH}_{3} \mathrm{SCH}_{3} \rightarrow \mathrm{H}_{2} \mathrm{O}+\mathrm{CH}_{3} \mathrm{SCH}_{2} \\
& \mathrm{OH}+\mathrm{CH}_{3} \mathrm{SCH}_{3} \rightarrow \mathrm{CH}_{3}+\mathrm{CH}_{3} \mathrm{SOH} \\
& \mathrm{OH}+\mathrm{CH}_{3} \mathrm{SCH}_{3} \rightarrow \mathrm{CH}_{3} \mathrm{~S}+\mathrm{CH}_{3} \mathrm{OH}
\end{aligned}
$$


$\mathrm{CH}_{3} \mathrm{~S}$ has been suggested to be an important intermediate in the oxidation of DMS. It can be obtained directly from reaction $(7 \mathrm{~d})$ of $\cdot \mathrm{OH}$ with DMS or indirectly from reaction $(7 \mathrm{~b})$, in presence of $\mathrm{O}_{2}$ and $\mathrm{NO}$, even in low amount, through the mechanism shown below:

$$
\begin{aligned}
& \mathrm{CH}_{3} \mathrm{SCH}_{2}+\mathrm{O}_{2}+\mathrm{M} \rightarrow \mathrm{CH}_{3} \mathrm{SCH}_{2} \mathrm{OO}+\mathrm{M} \\
& \mathrm{CH}_{3} \mathrm{SCH}_{2} \mathrm{OO}+\mathrm{NO} \rightarrow \mathrm{CH}_{3} \mathrm{SCH}_{2} \mathrm{O}+\mathrm{NO}_{2} \\
& \mathrm{CH}_{3} \mathrm{SCH}_{2} \mathrm{O}+\mathrm{M} \rightarrow \mathrm{CH}_{3} \mathrm{~S}+\mathrm{CH}_{2} \mathrm{O}+\mathrm{M}
\end{aligned}
$$

The addition of $\cdot \mathrm{OH}$ to DMS (7a) also appears to be an important pathway for dimethyl sulfide loss; in the absence of $\mathrm{O}_{2}$, the adduct would decompose rapidly to reform $\cdot \mathrm{OH}$; in the presence of $\mathrm{O}_{2}$, on the other hand, it will react with the molecular oxygen, mainly via one of the following reactions:

$$
\begin{aligned}
& \mathrm{OH} \cdot \mathrm{CH}_{3} \mathrm{SCH}_{3}+\mathrm{O}_{2} \rightarrow \mathrm{HO}_{2}+\mathrm{CH}_{3} \mathrm{~S}(\mathrm{O}) \mathrm{CH}_{3} \\
& \mathrm{OH} \cdot \mathrm{CH}_{3} \mathrm{SCH}_{3}+\mathrm{O}_{2} \rightarrow \mathrm{OH}+\mathrm{CH}_{3} \mathrm{~S}(\mathrm{O})_{2} \mathrm{CH}_{3}
\end{aligned}
$$

Other reactions involving the DMS·OH adduct are also possible. Reaction (11a) seems to be the predominant pathway of this reaction. The products of the reactions (11) are $\mathrm{CH}_{3} \mathrm{~S}(\mathrm{O}) \mathrm{CH}_{3}$ (dimethyl-sulfoxide) and $\mathrm{CH}_{3} \mathrm{~S}(\mathrm{O})_{2} \mathrm{CH}_{3}$ (dimethyl-sulfone). Both of them are known to rapidly react with $\mathrm{OH}$, and in presence of liquid water to be very likely removed by absorption in the liquid phase, because of their high solubility in water (the value of the Henry's law constant are $k_{H}>5 \cdot 10^{4}$ for both the compounds). It appears, from this mechanism, that sulfur-containing peroxy radicals are also produced; they also are much more soluble in water than dimethyl sulfide. In conclusion, the main effects of the oxidation of dimethyl sulfide are the formation of inorganic sulfur-containing compound, such as $\mathrm{SO}_{2}$ (that, however, is not detected in these experiments), and the production of intermediate oxidation byproducts, such as organic byproducts soluble in water. This result encourages the use of a heterogeneous system, such as the wet corona discharge, for removal of DMS and its oxidation byproducts.

\section{Removal of $\alpha$-Pinene by Pulsed Corona Discharge}

The industrial emissions of interest contain different terpenes; $\alpha$-pinene $\left(\mathrm{C}_{10} \mathrm{H}_{16}\right)$ is the one present in the most significant quantity; then it was selected for the laboratory tests. A series of experiments with constant corona reactor temperature equal to $200^{\circ} \mathrm{C}$ was conducted for three different concentrations.

The destruction efficiency is significantly dependent both on the concentration of $\alpha$-pinene and on the power input, as it is shown in Figure 9. For these experiments, the peak voltage was set to $10.3 \mathrm{kV}$ for $150 \mathrm{ppm}$, to $10.2 \mathrm{kV}$ for $400 \mathrm{ppm}$ and to $9.8 \mathrm{kV}$ for $800 \mathrm{ppm}$, in order to keep power consumption almost constant while changing the composition of the inlet gas. The SEI is in the level of $0.02,0.05$, and $0.01 \mathrm{kWh} / \mathrm{m}^{3}$ for frequency equal, respectively, to 266,667 , and $1450 \mathrm{~Hz}$. $\alpha$-pinene treatment with corona discharge yields high removal efficiency for a fairly low energy consumption level.

The study of the byproducts gives some insight on the mechanism of oxidation of $\alpha$-pinene. Different organic byproducts were detected by the chromatographic analysis. $\alpha$-pinene is a relatively large molecule; the organic carbons are not completely oxidized to inorganic compounds, such as $\mathrm{CO}$ or $\mathrm{CO}_{2}$, but, in some extent, are converted to oxidized organic compounds. Only two of these compounds were identified: methanol and acetone. Methanol is present only in small amounts, while acetone is produced in much more significant quantities, as shown in Table 5. Acetone concentration depends on the initial concentration of $\alpha$-pinene and on the SEI; it actually increases with increase of these two factors, since it depends on the amount of $\alpha$-pinene oxidized and this amount increases both with the initial concentration and the SEI.

$\alpha$-pinene, as the other terpenes, is highly reactive with ozone and hydroxyl radicals [16,17]. Suggested mechanisms of $\cdot \mathrm{OH}$ and ozone initiated oxidation show good agreement with the experimental results obtained in this work. Both mechanisms predict that a number of oxidized organic compounds (including $\mathrm{C}_{10}, \mathrm{C}_{9}$ and smaller molecules) are produced from the oxidation of $\alpha$-pinene. 


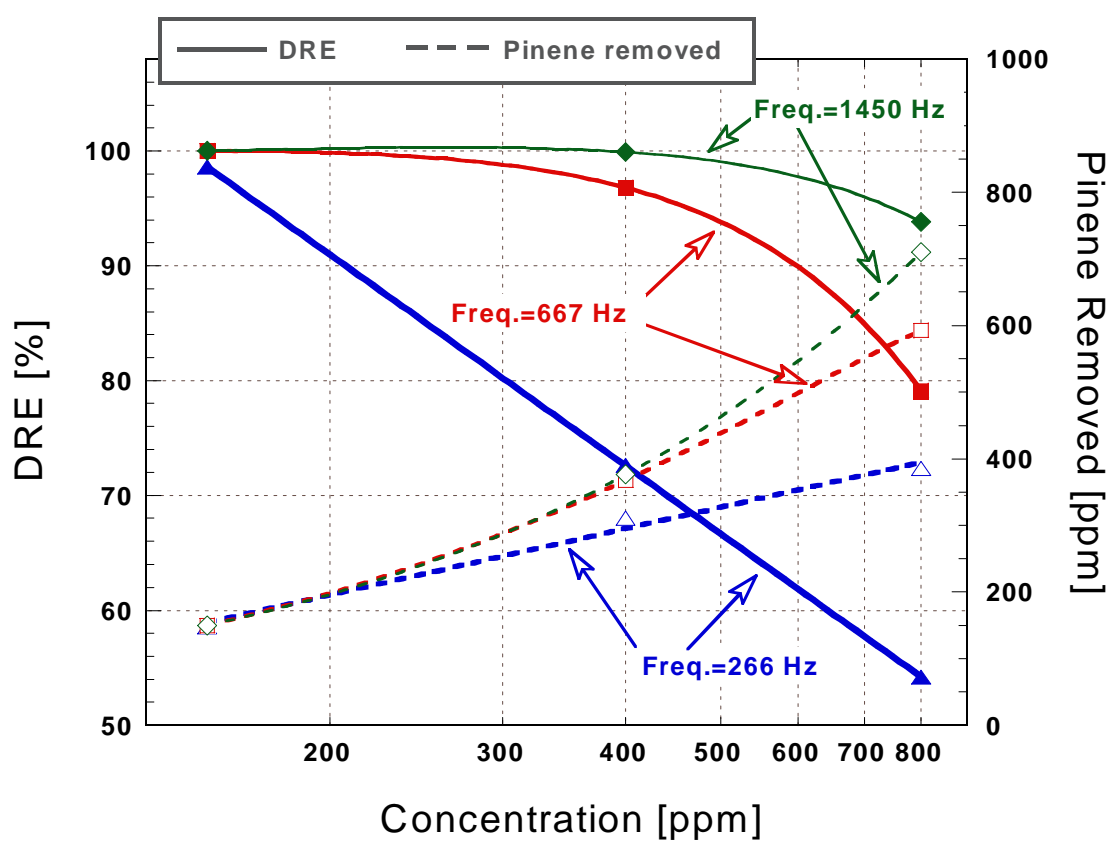

Figure 9. DRE and actual amount of $\alpha$-pinene removed as a function of the initial concentration of $\alpha$ pinene.

Table 5. Acetone concentration [ppm] as byproduct of the destruction of $\alpha$-pinene.

\begin{tabular}{|c|c|c|c|c|}
\hline \multirow{2}{*}{ Power $[\mathrm{W}]$} & \multicolumn{3}{|c|}{ Initial Concentration of $\alpha$-Pinene [ppm] } & \multirow{2}{*}{$\begin{array}{l}\text { Mean SEI } \\
{\left[\mathrm{KWh} / \mathrm{m}^{3}\right]}\end{array}$} \\
\hline & 150 & 400 & 800 & \\
\hline 3.4 & $\sim 2$ & $\sim 88$ & $\sim 81$ & 0.022 \\
\hline 7.3 & $\sim 49$ & $\sim 120$ & $\sim 167$ & 0.05 \\
\hline 12.4 & $\sim 60$ & $\sim 128$ & $\sim 220$ & 0.099 \\
\hline
\end{tabular}

The mechanism of ozonolysis of $\alpha$-pinene proceeds via addition of $\mathrm{O}_{3}$ to the double bond, leading initially to the formation of an energy-rich ozonide, which rapidly decomposes to form some of the $\mathrm{C}_{10}$ byproducts, such as pinonic acid and pinonaldehyde. Pinonaldehyde is considered to have, at atmospheric conditions, the highest molar yield among the $\mathrm{C}_{10}$ byproducts equal to about $17 \%$ of the initial $\alpha$-pinene. Further decomposition processes, involving elimination of organic carbons in the form of organic or inorganic compounds, yield to the formation of smaller organic byproducts. Among these byproducts, acetone is supposed to account for about $6 \%$ of the initial $\alpha$-pinene.

A mechanism that explains the formation of acetone from $\cdot \mathrm{OH}$-initiated oxidation of $\alpha$-pinene involves four distinct consecutive steps. The first step is the (barrierless) addition of the $\cdot \mathrm{OH}$ radical onto the double bond with the formation of a tertiary adduct radical $(\mathrm{PlOH})$. The second step involves isomerization reactions of the tertiary radical. In the next step, these isomeric radicals will rapidly react with $\mathrm{O}_{2}$, followed, in conditions with presence of $\mathrm{NO}$, by the addition of $\mathrm{NO}$, and, for the most part, elimination of $\mathrm{NO}_{2}$, forming the oxy-radicals. Finally, acetone can be formed by rupture of the $\beta \mathrm{C}-\mathrm{C}$ bond of this radical. This mechanism involves the presence of NO in the reacting gas. The concentration of $\mathrm{NO}$ was not measured in these experiments, but $\mathrm{NO}_{\mathrm{x}}$ is known to be produced in electric discharges. This $\mathrm{OH}$-initiated oxidation mechanism predicts the acetone concentration to be in the range 4$20 \%$ of the initial concentration of $\alpha$-pinene. As already mentioned before, even though several organic byproducts were detected by the GC, only a few of them (i.e. acetone and methanol) could be identified since the GC was not calibrated for the other hydrocarbons detected. In the $\mathrm{GC}$ analysis, some of the unidentified organic byproducts were eluted at about the same time as $\alpha$-pinene, some of them even after $\alpha$-pinene, proving that organic molecules with a number of carbons equal or slightly smaller than $\alpha$-pinene (i.e. $\mathrm{C}_{10}$ or $\mathrm{C}_{9}$ ) were actually produced. The actual acetone concentration measured in the experiments is in the interval of $4-35 \%$ from the initial concentration of $\alpha$ - 
pinene. This result suggest that oxidation processes initiated by the $\cdot \mathrm{OH}$ radicals appear to be a major pathway for oxidation of $\alpha$-pinene, but reactions with other types of active species are also taking place.

For a concentration of $\alpha$-pinene on the level of $400 \mathrm{ppm}$, two additional series of experiments were run with temperature and humidity as parameters. In the first series of experiments, temperature was varied from $70^{\circ} \mathrm{C}$ to $200^{\circ} \mathrm{C}$, for pulse frequency equal to $667 \mathrm{~Hz}$. In the second series, the flow rate of liquid water was varies from 0 to $0.75 \mathrm{ml} / \mathrm{min}$ for pulse frequency equal to $1000 \mathrm{~Hz}$. Results from these experiments are presented in Table 6 and Table 7 , respectively.

Table 6. Effect of temperature on the removal of $\alpha$-pinene

\begin{tabular}{|c||c|c|c|c|c|}
\hline \multicolumn{1}{|c||}{} & \multicolumn{5}{c|}{ Temperature [C] } \\
\cline { 2 - 6 } & $\mathbf{7 0}$ & $\mathbf{1 0 0}$ & $\mathbf{1 3 0}$ & $\mathbf{1 7 0}$ & $\mathbf{2 0 0}$ \\
\hline \hline DRE [\%] & 76.6 & 81.5 & 84 & 89.7 & 96.4 \\
\hline SEI $\left[\mathbf{k W h} / \mathbf{m}^{3}\right]$ & 0.047 & 0.048 & 0.0485 & 0.049 & 0.05 \\
\hline$\chi[\mathbf{k W h} / \mathbf{K g}]$ & 25.49 & 24.17 & 23.65 & 22.53 & 21.43 \\
\hline Acetone Conc. $[\mathbf{p p m}]$ & 44 & 55 & 59 & 88 & 189 \\
\hline
\end{tabular}

Table 7. Effect of humidity on the removal of $\alpha$-pinene

\begin{tabular}{|c||c|c|c|c|}
\hline \multicolumn{1}{|c|}{} & \multicolumn{4}{c|}{ Water Flow Rate [ml/min] } \\
\cline { 2 - 5 } & $\mathbf{0}$ (dry) & $\mathbf{0 . 1}$ & $\mathbf{0 . 2 5}$ & $\mathbf{0 . 7 5}$ \\
\hline \hline DRE [\%] & 98.2 & 97.4 & 97.3 & 97.3 \\
\hline SEI [KWh/m $\left.\mathbf{m}^{3}\right]$ & 0.062 & 0.06 & 0.057 & 0.056 \\
\hline$\chi[\mathbf{k W h} / \mathbf{K g}]$ & 25.81 & 25.18 & 24.22 & 23.59 \\
\hline Acetone Conc. $[\mathbf{p p m}]$ & $\sim 96$ & $\sim 100$ & $\sim 107$ & $\sim 114$ \\
\hline
\end{tabular}

A decrease of about $25 \%$ in the value of DRE is obtained by lowering temperature from $200^{\circ} \mathrm{C}$ to $70^{\circ} \mathrm{C}$, while the SEI is decreased only by approximately $6 \%$. The final result is a $16 \%$ increase in the value of the Energy Price, suggesting that the decrease in DRE is not due only to the lower SEI but also to changes in the chemical kinetics of the oxidation reactions between the $\alpha$-pinene molecules and the active species produced by the electric discharge. The Energy Price expressed in [kWh/kg] turns out to be significantly lower (about 10 times lower) than the Energy Price calculated for the destruction of methanol, while the SEI is about the same; this is due to the fact that it is calculated with respect to the actual mass of VOC removed, while the SEI is related to the flow rate of gas treated by plasma discharge. Given the same amount of VOC by volume, the mass of $\alpha$-pinene is comparatively higher than the mass of methanol, because of the higher molecular weight.

A change in the liquid flow rate has insignificant effect on the DRE, with a variation contained in a $1 \%$ range. This change has a more significant effect on the amount of power consumed, which actually decreases for higher water flow rates. Then, despite the slight reduction in the removal efficiency, an increase of the water flow rate appears to be advantageous from the standpoint of the Energy Price. In comparison with an experimental condition with completely dry air, the Energy Price decreases by about $6 \%$ with water flow rate equal to $0.75 \mathrm{ml} / \mathrm{min}$.

Also the production of acetone appears to be dependent on temperature and humidity variations, as presented in Table 6 and Table 7. The amount of acetone increases significantly when temperature is raised; this increase accompanies the growth in the removal rate of $\alpha$-pinene. Humidity also affects the production of acetone; when increasing the water flow rate, the concentration of acetone rises, while, in this case, the destruction rate of $\alpha$-pinene is fairly constant or slightly decreasing. In this case the increase in acetone production is probably due to the decrease of the power consumption. When power decreases, a smaller amount of the destroyed $\alpha$-pinene is completely oxidized to an inorganic species, because of the power requirements to complete the oxidation process; a bigger amount of the intermediate, partially oxidized species, such as acetone or other organic compounds, is produced. 
In conclusion, from the industrial standpoint, the goal of $98 \%$ removal for a composition comparable to the brownstock washer emission (about $200 \mathrm{ppm}$ ) can be reached with the lowest SEI supplied to the discharge (about $\left.0.025 \mathrm{kWh} / \mathrm{m}^{3}\right)$.

\section{Results of the Experiments with VOC Mixtures}

The objective of the analysis with the complete mixture is to show the viability of the application of this type of discharge for removing VOCs from a gas stream with a composition as close as possible to the brownstock washer emissions from a paper plant. In this case, the initial composition of the gas stream has been fixed as: 100 ppm of methanol, $20 \mathrm{ppm}$ of acetone, $200 \mathrm{ppm}$ of $\alpha$-pinene and $20 \mathrm{ppm}$ of dimethyl sulfide. The GC was calibrated with a certified gas mixture with this composition. Corona frequency was used as the only parameter. Temperature of the corona reactor was kept constant, set to $200^{\circ} \mathrm{C}$. Peak voltage was set equal to $12.3 \mathrm{kV}$. Water was introduced, at a flow rate equal to $0.25 \mathrm{ml} / \mathrm{min}$, and it was completely vaporized in the mixing chamber.

Two different types of experiments were performed; at first, only the soluble compounds were provided, supplied in water solution with a HPLC pump; $\alpha$-pinene, which is practically insoluble in water, could not be supplied for these experiments. For the second series of experiments, the certified gas mixture was used in such a way that $\alpha$-pinene could also be included in the study. The values of removal efficiency resulting from all these experiments are presented in Table 8. For these experiments the level of the power provided to the system is higher than for the experiments with the single VOCs, given that the peak voltage is set to a higher value.

AS in the experiments with the single VOCs, high removal efficiency can be reached also for all the VOCs when dealing with mixtures containing more than one compound. Methanol and dimethyl sulfide turn out to be easily removable, and $100 \%$ efficiency is achieved when the mixture not containing $\alpha$-pinene is treated. From the comparison between the results obtained from these two different types of experiments, it appears that, in presence $\alpha$-pinene, the removal rate of the other compounds decreases; in particular, it seems that only a small amount of acetone is destroyed by the corona discharge. This is due to the byproducts generated by the destruction of $\alpha$-pinene. It was already pointed out that $\alpha$-pinene, being an organic molecule containing ten carbon atoms, partially oxidizes to other smaller organic compounds, such as methanol and, in a larger amount, acetone. Then, acetone and methanol concentrations in the gas stream are determined not only by the amount that is initially supplied but also significantly by the quantity that is produced as a consequence of the destruction of $\alpha$-pinene. The presence of other organic byproducts is shown in the chromatographic analysis, but most of them could not be positively identified.

Table 8. DRE [\%] and SEI $\left[\mathrm{kwh} / \mathrm{m}^{3}\right]$ for treatment of VOC mixtures in regular corona discharge.

\begin{tabular}{||c||c|c||c|c||}
\hline \multicolumn{1}{|c||}{} & \multicolumn{2}{c||}{ Mixture with water soluble VOCs } & \multicolumn{2}{c|}{ Complete Mixture } \\
\cline { 1 - 3 } Frequency $\rightarrow$ & $\mathbf{6 6 7}$ & $\mathbf{1 4 5 0}$ & \multicolumn{2}{c|}{$\mathbf{1 4 5 0}$} \\
\hline \hline Methanol & DRE & DRE & 86.51 & 23.05 \\
\hline Acetone & 100 & 100 & 14.51 & SEI \\
\cline { 1 - 3 } DMS & 91.11 & 99.30 & 83.81 & 0.192 \\
\hline $\boldsymbol{\alpha}$-Pinene & 100 & 100 & 96.52 & \\
\hline \hline
\end{tabular}

\section{Discussion on the Results of VOC Removal by Pulsed Corona Discharge}

VOC removal from HVLC gas streams by pulsed corona discharge was experimentally assessed, showing that high destruction and removal efficiency can actually be obtained with fairly low power consumption. It is interesting to observe that for most of the experimental conditions, data on the destruction and removal efficiency can be closely curve-fitted by a negative exponential curve as function of the specific energy input, as it is shown in Figure 3 and Figure 4. We can write the fitting equation as:

$$
D R E=A \cdot\left(1-e^{-(S E I / \alpha)}\right)
$$


where $A$ and $\alpha$ are the parameters of the curve-fit; $A$ represents the limit value of removal efficiency increasing the supplied power. In the same way the final concentration of VOCs are fairly accurately curve-fitted by negative exponential lines, with almost the same slope for high initial VOC concentration.

The value of the exponential folding factor $\alpha$ was shown (in previous works by Rosocha [3] and by Penetrante [12]) to be nearly constant, for the highest concentrations in the range of these experiments, independent of the concentration itself. Results from these experiments are in good agreement with this behavior of VOC destruction, as it is shown in Figure 3, Figure 4 and Figure 8.

Energy Price for the removal of VOCs was previously expressed in terms of $\mathrm{kWh}$ per $\mathrm{kg}$ of organic compound removed from the gas phase. For plasma technologies, another common unit for defining the energy price to decompose organic molecules is the $\mathrm{eV}$ per molecule. Energy Price significantly depends on the initial concentration of VOC in the gas stream. For very low VOC concentrations, in the order of few ppm, the energy price reaches very high values, on the level of thousands of eV per molecule. This is due to the fact that not all the active species produced in the gas discharge can actually target VOC molecules, i.e. not all the electric energy that is used to create these active species is directed to oxidation of organic compounds; some of these species undergo reactions with different molecules or lose their energy via other processes (recombination, relaxation, etc.). Reactions with VOCs are statistically more frequent if the concentration of these compounds is relatively high; in this case, the fraction of energy "usefully" spent for the purpose of removing pollutant molecules is higher and the energy spent for the elimination of each single molecule decreases.

We can consider as Energy Cost for the destruction of a given VOC, the amount of SEI equal to the coefficient $\alpha$. Values of the Energy Cost are presented in Figure 10; they could be defined only for those initial concentrations of VOC such that complete destruction is not obtained at least for the smallest power supplied. This graph shows the presence of a threshold concentration for VOCs (concentration that is actually different for each VOC, but approximately equal $200 \mathrm{ppm}$ for all the compounds): above this threshold value, the Energy Cost becomes fairly constant, meaning that in these conditions the concentration of VOC is not a limiting factor for the reactions with the active species produced in the plasma. The value of Energy Cost in this range of concentrations is on the level of 20$60 \mathrm{eV} /$ molecule depending on the type of VOC, as it is shown in the zoom-window of Figure 10.

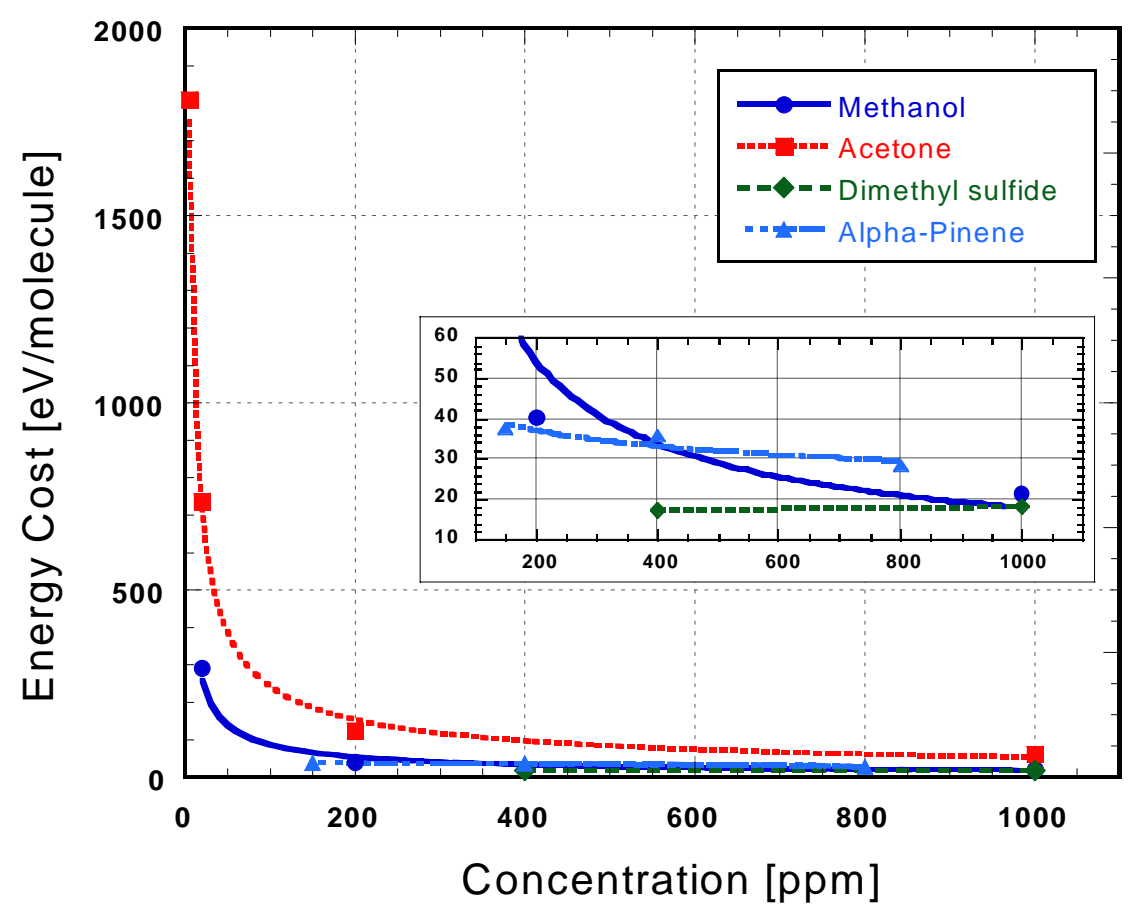

Figure 10. Energy Cost for the treatment of VOCs with the pulsed corona discharge 
Figure 11 also shows another parameter that is often used to measure the efficiency of discharge processing for decomposing VOCs: the G-value. The G-value indicates the number of VOC molecules attacked and destroyed by the active species per $100 \mathrm{eV}$ of energy input. In the figure, for each compound, the G-value is represented with the same type of marks and line styles as the Energy Cost, but marks are not filled and lines are thin for the G-value.

The G-value, such as the energy price, depends both on the type of discharge in use and, taken a particular kind of discharge, on the actual setup and experimental conditions. For high concentrations of VOCs, the obtained G-values are comparable to the G-values presented in the literature [6] for ionization and dissociation processes, i.e. for those processes that induce the formation of active species, suggesting that, at least for VOC concentration higher than the threshold value, reactions between organic molecules and these species are just limited by the rate of formation of the latter, and not by the concentration of organic compounds.

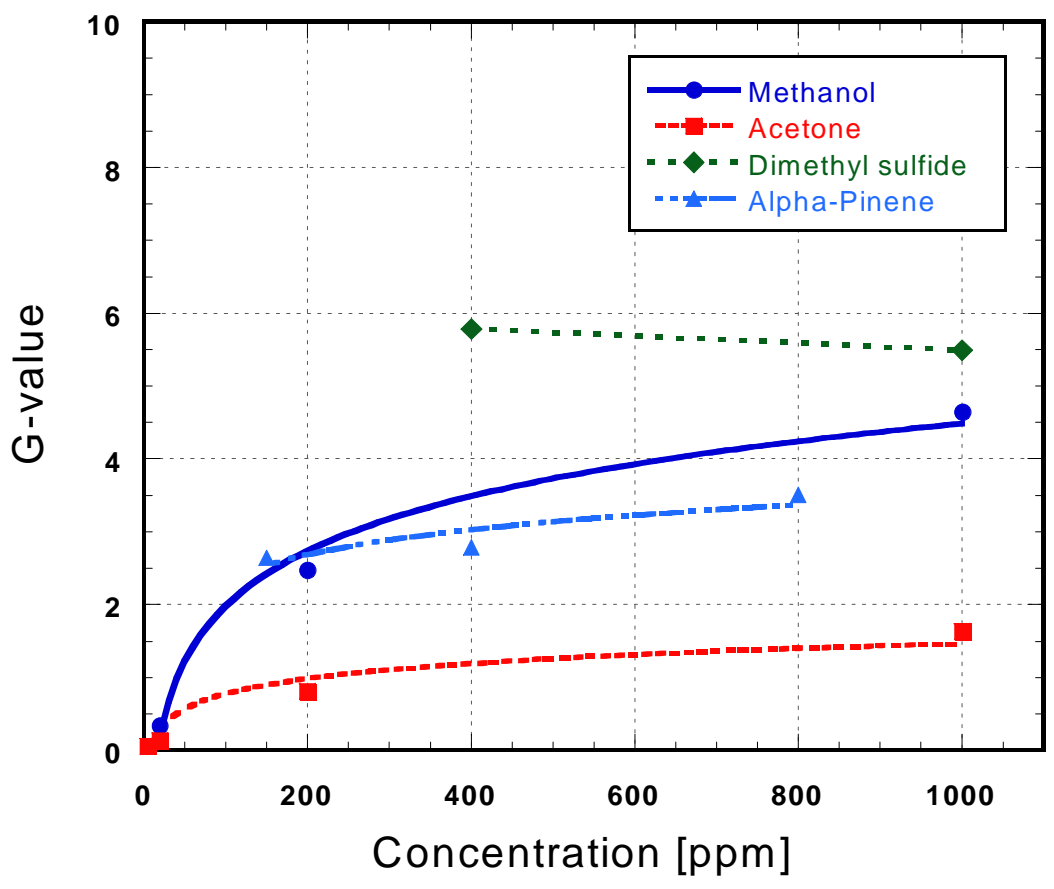

Figure 11. G-values for the treatment of VOCs with the pulsed corona discharge

\section{Wet Pulsed Corona Discharge - Experimental Results}

A wet pulsed corona discharge has also been tested for the destruction of VOCs, looking for a synergetic effect of plasma-induced oxidation and absorption into liquid phase for removing the pollutant compounds from the gas phase. Water was introduced as a thin layer or film flowing on the internal wall of the corona reactor.

The solubility of a gas in water is described by the Henry's law, which states a relation between the concentrations of a gas in the liquid and in the gas phases. The Henry's law constant $\mathrm{k}_{\mathrm{H}}$ is defined as:

$$
k_{H}=\frac{c_{a}}{p_{g}}
$$

Here, $c_{a}$ is the concentration of a species in the aqueous phase and $p_{g}$ is the partial pressure of that species in the gas phase. 
The higher the value of the Henry's law constant for a given compound, the higher is the solubility of that compound in water. Values of the Henry's law constants for the VOCs of interest in this work are shown in Table 9. Oxidized compounds, such as methanol, acetone and the intermediate byproducts from the oxidation of dimethyl sulfide and $\alpha$-pinene appear to have a much higher solubility than the non-oxidized species.

Table 9. Henry's law constant values in standard conditions

\begin{tabular}{|ll|c|}
\hline & & $k_{H}^{\Theta}$ \\
\hline Methanol & $\mathrm{CH}_{3} \mathrm{OH}$ & $2.2 \cdot 10^{2}$ \\
\hline Acetone & $\mathrm{CH}_{3} \mathrm{COCH}$ & $3.1 \cdot 10^{1}$ \\
\hline Dimethyl Sulfide & $\mathrm{CH}_{3} \mathrm{SCH}_{3}$ & $9 \cdot 10^{-1}$ \\
\hline a-Pinene & $\mathrm{C}_{10} \mathrm{H}_{16}$ & $4.9 \cdot 10^{-2}$ \\
\hline Butane & $\mathrm{C}_{4} \mathrm{H}_{10}$ & $1.2 \cdot 10^{-3}$ \\
\hline Sulfur Dioxide & $\mathrm{SO}_{2}$ & $1.2 \cdot 10^{1}$ \\
\hline
\end{tabular}

In order to assess the efficiency of the wet corona discharge for the VOC removal, experiments were performed with the single compounds. The wet corona reactor was not placed into a furnace; hence reactor temperature could not be used as experimental parameter. For these experiments, a gas flow rate of 1 SLM was used. It is twice smaller than the flow rate used for the experiments in the regular corona, to ensure the same residence time as in the 'dry' corona reactor, given that this 'wet-type' reactor is twice as short as the previous one. Experiments were performed to test the removal of methanol, acetone, dimethyl sulfide, $\alpha$-pinene, sulfur dioxide, and butane. Sulfur dioxide was used with the purpose of testing the possibility of removing inorganic sulfur compounds obtained from the oxidation of dimethyl sulfide. Butane was used to show the existence of a synergetic effect plasma/water film in the removal of an insoluble $\left(k_{H}=1.2 \cdot 10^{-3}\right)$, non-oxidized hydrocarbon. For most of the experiments, water vapor was also introduced into the reactor.

In order to gain a better understanding of the experimental results, a quasi two-dimensional model of VOCs absorption into water was developed. The model is based on the solution of the species conservation equations for the gas phase and for the liquid phase. It yields to the following expression for the Destruction and Removal Efficiency:

$$
D R E=\frac{(1-\alpha) \cdot e^{-\beta(1-\alpha)}}{1-\alpha \cdot e^{-\beta(1-\alpha)}}
$$

where $\beta$ is the ratio between the convection time and the diffusion time and can be written as:

$$
\beta=\frac{4 \tau_{c}}{\tau_{d}}=\frac{\left(D / d^{2}\right)}{\left(V_{g} / L\right)}
$$

with: $\mathrm{D}=$ diffusion coefficient in air; $\mathrm{d}=$ electrode separation distance; $\mathrm{V}_{\mathrm{g}}=$ velocity of the gas; $\mathrm{L}=$ length of the wet corona reactor.

while $\alpha$ is a ratio between gas and liquid flow rate and is expressed as:

$$
\alpha=\frac{Q_{g}}{Q_{w} V_{m o l} k_{H}} \text { (19) }
$$

with: $\mathrm{Q}_{\mathrm{g}}=$ gas flow rate; $\mathrm{Q}_{\mathrm{w}}=$ water flow rate; $\mathrm{V}_{\mathrm{mol}}=$ gas volume per unit mole.

With the assumption, which holds true for these experiments, that the convection time is much longer than the diffusion time, i.e. $\beta>>1, \alpha$ becomes the critical parameter: for $\alpha>1$, the DRE is very low, while for $\alpha<1$ high values of DRE are obtained. Since the gas flow rate is fixed for these experiments and $\mathrm{V}_{\mathrm{mol}}$ and $\mathrm{k}_{\mathrm{H}}$ are constant in standard conditions, assuming $\alpha=\alpha_{\text {crit }}=1$, a critical value for the water flow rate can be derived as:

$$
Q_{w-c r i t}=\frac{Q_{g}}{V_{m o l} k_{H}}
$$


Only a flow rate higher than this critical value provides a high removal of a given substance by absorption into the water film. This theoretical analysis shows good agreement with the experimental results presented below.

\section{Removal of Methanol and Acetone by Wet Pulsed Corona Discharge}

Methanol removal by absorption into water and by plasma-induced oxidation was studied in the wet corona reactor. An initial concentration equal to $200 \mathrm{ppm}$ of methanol was considered. Methanol is the most soluble among the organic compounds of interest, as Table 9 shows. The value of the critical water flow rate for absorbing methanol was calculated from the model to be $Q_{w-\text { crii }} \sim 0.2 \mathrm{ml} / \mathrm{min}$, in good agreement with the experimental results shown in Figure 12. For a fairly low flow rate of the water film $(\sim 0.9 \mathrm{ml} / \mathrm{min})$, the DRE is almost complete (about $99.9 \%$ ), suggesting that an optimal configuration in terms of the geometry of the reactor and of the ratio between gas and liquid flow rate has been obtained for the removal of methanol. On the other hand, the results attained from the destruction of methanol in the wet corona setup, without the presence of any water film, are presented in Table 10. The SEI is generally higher than in the regular corona experiments, because of the smaller gas flow rate. The SEI, however, can be reduced (as it is shown below for the experiments with dimethyl sulfide) by decreasing the corona frequency and the peak voltage, which was set to fairly high values of about $11 \mathrm{kV}$ for these experiments. DRE values are higher than those obtained from methanol removal in the regular corona reactor at the same temperature. In tests with the regular corona, for experiments performed at the temperature of $70^{\circ} \mathrm{C}$ and $667 \mathrm{~Hz}$ as corona frequency, DRE is equal to $53.3 \%$, with SEI equal to $0.044 \mathrm{kWh} / \mathrm{m}^{3}$. For wet corona experiments, the DRE is already higher than $60 \%$ for an energy input of about $0.034 \mathrm{kWh} / \mathrm{m}^{3}$. This is probably due to the geometry of the reactor itself and to some different technical solution adopted to build it.

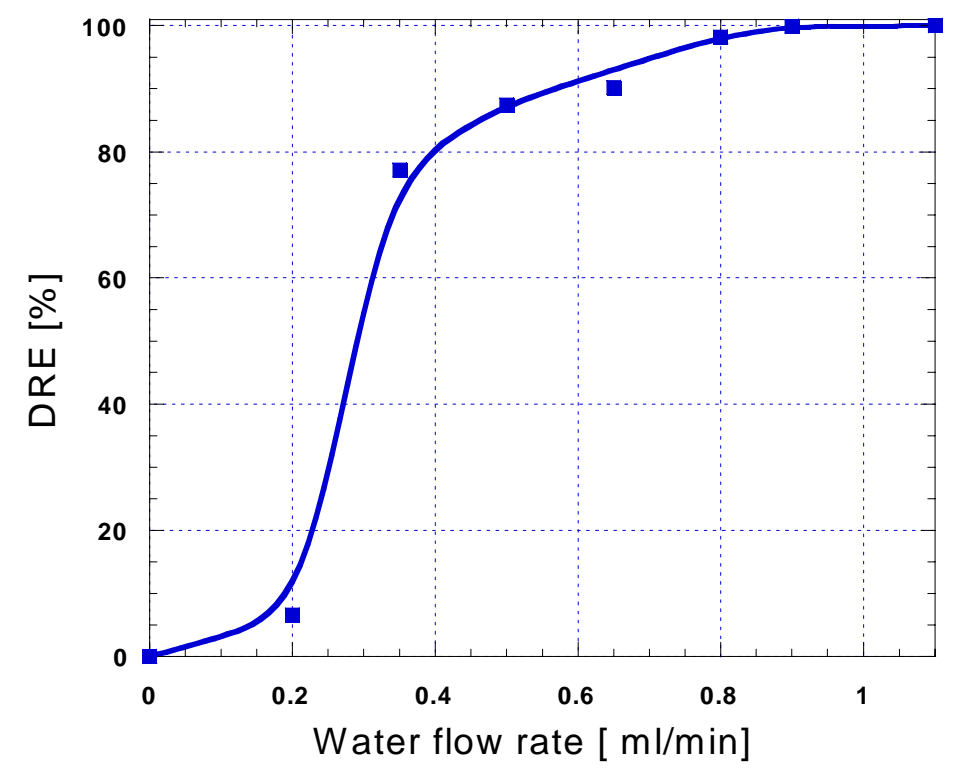

Figure 12. DRE of methanol by absorption into water as a function of the flow rate of the water film

Table 10. DRE $[\%]$ and SEI $\left[\mathrm{kwh} / \mathrm{m}^{3}\right]$ for treating $200 \mathrm{ppm}$ of methanol in the wet corona reactor, without water film.

\begin{tabular}{|c||c|c|}
\hline Frequency [Hz] & DRE & SEI \\
\hline \hline $\mathbf{2 6 6}$ & 62.3 & 0.034 \\
\hline $\mathbf{6 6 7}$ & 84.5 & 0.083 \\
\hline $\mathbf{1 4 5 0}$ & 97.6 & 0.193 \\
\hline
\end{tabular}

Acetone removal by absorption into water was studied for flow rate of the water film varying from 0 to about 2 $\mathrm{ml} / \mathrm{min}$, without the corona discharge. The initial concentration of acetone in the gas stream was $200 \mathrm{ppm}$. For 
acetone, with a 1 SLM gas flow rate, the calculated value of the critical water flow rate is $Q_{w-c r i t} \sim 1.3 \mathrm{ml} / \mathrm{min}$, experimental results, presented in Figure 13, show good agreement with the theoretical calculations.

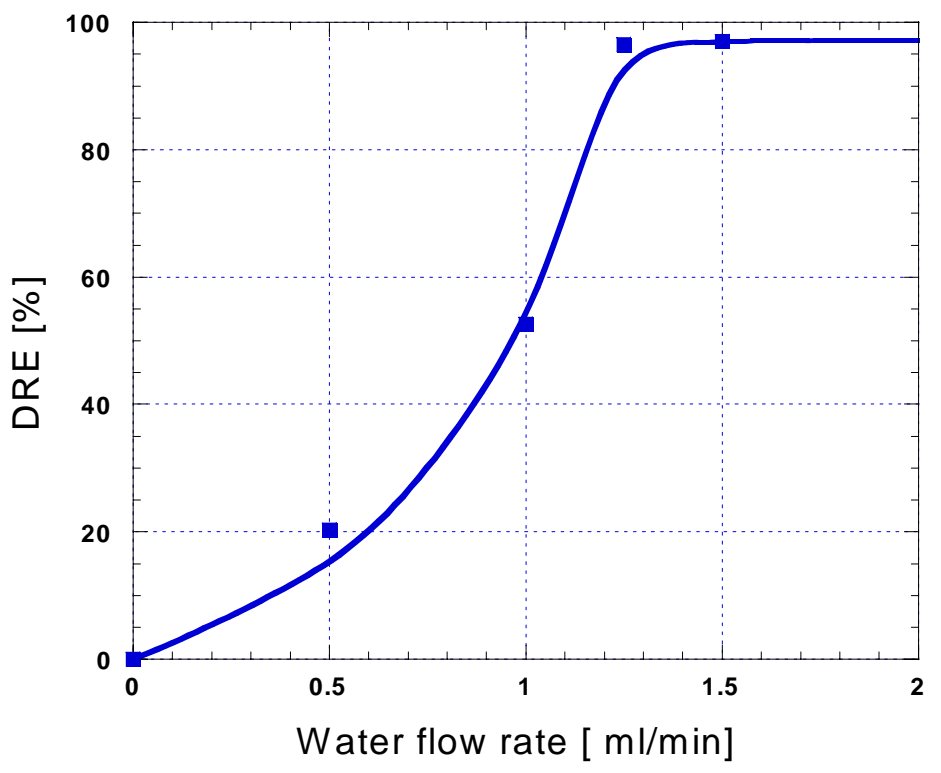

Figure 13. DRE of acetone by absorption into water as a function of the flow rate of the water film.

In conclusion, absorption into water of compounds with high Henry's law constants, such as methanol and acetone, appears to be a very feasible solution given the low water flow rate required, which is, by weight, comparable to the gas flow rate or even lower; absorption is economically practical for the removal of these compounds from industrial gas streams when water is readily available (as in the case of the paper and wood industry).

\section{Removal of Butane by Wet Pulsed Corona Discharge}

Butane is the least soluble among the compounds tested. Experiments were carried out on the treatment of a gas stream containing $300 \mathrm{ppm}$ of butane. Corona frequency was $667 \mathrm{~Hz}$ (i.e. obtaining SEI $0.08 \mathrm{kWh} / \mathrm{m}^{3}$ ).

Results from these experiments are presented in Table. They show that a significant role in the oxidation of butane is played by active species produced by the corona discharge in presence of water vapor, such as the $\mathrm{OH}$ radicals. In fact, when moist air is treated, the removal efficiency of butane appears to be almost twice as high as in the dry condition. On the other hand, the introduction of the water film, with different flow rate, does not significantly improve the removal efficiency of butane; this is due to the extremely low solubility of butane into water.

Among the byproducts of the oxidation of butane, small amounts of organic compounds were detected. Among these compounds, only acetone and methanol were positively identified and quantified (Table 11). Introducing a film of water reduces their amount, but the level of the reduction is not as significant as expected, especially for methanol. This can be explained reminding that, unlike the previous tests, methanol and acetone are not introduced into the reactor, but are produced by the oxidation of butane inside the reactor. Since butane is not completely oxidized for any of the experimental conditions (i.e. DRE $<100 \%$ for all the tests performed), the oxidation of this hydrocarbon and the production of byproducts such as acetone and methanol occurs along the entire reactor; then, the results obtained from the theoretical calculations, which draw to the conclusion that a critical value of water flow rate exists and determine it, are not valid anymore, since the assumption of convective time much greater than the diffusion time is not valid anymore. In fact, in this case all the parameters in the expressions for $\alpha$ and $\beta$ keep the same values except $L$, which cannot be considered equal to the length of the reactor, but only to some "effective length of absorption", smaller than the overall length of the reactor. Therefore, $\beta$ cannot be considered greater than unity and then $\alpha$ is not a critical parameter anymore. The methanol and acetone molecules that are produced close to 
the end of the reactor do not have any possibility to get absorbed into the film of water or to be oxidized to inorganic molecules as $\mathrm{CO}_{2}$; they will escape from the reactor and be detected by the GC.

Table 11. DRE [\%] of butane and methanol and acetone concentrations [ppm] in the exhaust gas obtained from the treatment of a gas stream containing $300 \mathrm{ppm}$ of butane.

\begin{tabular}{|c|c|c|c|c|c|c|c|}
\hline \multirow{2}{*}{} & \multirow{2}{*}{$\begin{array}{c}\text { Water film } \\
\text { flow rate } \\
{[\mathrm{ml} / \mathrm{min}]}\end{array}$} & \multicolumn{6}{|c|}{ Corona Frequency [Hz] } \\
\cline { 3 - 8 } & & \multicolumn{3}{|c|}{$\mathbf{2 6 6}$} & \multicolumn{4}{|c|}{$\mathbf{6 6 7}$} \\
\cline { 3 - 8 } & - & 11.7 & $\sim 22$ & $\sim 3$ & 22.6 & $\sim 31$ & $\sim 3$ \\
\hline \hline $\begin{array}{c}\text { Without water film- } \\
\text { dry air }\end{array}$ & - & - & - & - & 42.7 & $\sim 68$ & $\sim 8$ \\
\hline $\begin{array}{c}\text { Without water film- } \\
\text { moist air }\end{array}$ & - & - & - & - & 47.3 & $\sim 62$ & $\sim 3$ \\
\hline $\begin{array}{c}\text { With water film- } \\
\text { moist air }\end{array}$ & 0.5 & - & - & - & 48.4 & $\sim 61$ & $\sim 2$ \\
\hline $\begin{array}{c}\text { With water film- } \\
\text { moist air }\end{array}$ & 1.2 & - & Mcet. & DRE & Meth. & Acet. \\
\hline \hline
\end{tabular}

The levels of reduction of methanol and acetone are different; the removal of methanol appears to be lower than the removal of acetone, contrary to what expected; this suggests that the effective lengths of absorption of these two compounds are different: the effective absorption length of methanol is shorter than the one of acetone. It suggests that, in the process of oxidation of butane, methanol is mainly produced later than acetone or it is produced closer to the end of the reactor.

\section{Removal of Dimethyl Sulfide and $\mathrm{SO}_{2}$ by Wet Pulsed Corona Discharge}

The removal of dimethyl sulfide (DMS) was studied, testing a moist gas stream containing $400 \mathrm{ppm}$ of dimethyl sulfide. Corona frequency and flow rate of the water film were used as experimental parameters; they were varied up to $1450 \mathrm{~Hz}$ and $6 \mathrm{ml} / \mathrm{min}$ respectively. Peak voltage was kept constant at $9 \mathrm{kV}$. Experimental results are presented in Table 12. DMS appears to be fairly insoluble. The presence of a water film does not affect the removal of dimethyl sulfide significantly. For the removal of DMS, then, absorption into water does not seem to be a viable solution for practical application: a large amount of water that would be necessary to reach an acceptable level of removal, given the small value of the Henry's law constant. Oxidation of DMS via the corona discharge is then required.

Table 12. DRE [\%] and SEI $\left[\mathrm{kwh} / \mathrm{m}^{3}\right]$ for treatment of $400 \mathrm{ppm}$ of dimethyl sulfide in the wet pulsed corona reactor

\begin{tabular}{|c||c|c|c|c|c|c|c|c|c|c||}
\hline \multirow{2}{*}{ Frequency [Hz] } & \multicolumn{9}{|c|}{ Water Flow Rate [mI/min] } \\
\cline { 2 - 13 } & \multicolumn{2}{|c|}{ No film } & \multicolumn{2}{|c|}{$\mathbf{0 . 2}$} & \multicolumn{2}{|c|}{ 0.8 } & \multicolumn{2}{|c|}{$\mathbf{2 . 5}$} & \multicolumn{2}{|c|}{$\mathbf{6}$} \\
\cline { 2 - 13 } & DRE & SEI & DRE & SEI & DRE & SEI & DRE & SEI & DRE & SEI \\
\hline \hline $\mathbf{0}$ & - & - & - & - & - & - & - & - & 28 & - \\
\hline $\mathbf{2 3 2}$ & 67.0 & 0.026 & 68.7 & 0.022 & 68.9 & 0.023 & 71.5 & 0.024 & 62 & 0.023 \\
\hline $\mathbf{2 6 6}$ & 88.1 & 0.031 & - & - & - & - & - & - & - & - \\
\hline $\mathbf{5 0 0}$ & 92.4 & 0.052 & 92.4 & 0.049 & 93.0 & 0.049 & 94.9 & 0.048 & 95.9 & 0.048 \\
\hline $\mathbf{1 4 5 0}$ & 100 & 0.133 & 100 & 0.137 & 100 & 0.140 & 100 & 0.142 & 100 & 0.140 \\
\hline
\end{tabular}


As already shown by experiments performed in the regular corona reactor, the DRE of dimethyl sulfide is strongly influenced by the power level. Even though these experiments are performed at a temperature significantly lower than the tests in the regular corona, it is still possible to obtain complete removal of dimethyl disulfide by increasing the power of the corona discharge in order to have SEI in the level of $0.1 \mathrm{kWh} / \mathrm{m}^{3}$.

Organic byproducts were detected and methanol was identified; the concentration of methanol in the exhaust gas for the different values of frequency and water flow rate is shown in Figure 14. In the presence of the water film, the variation of methanol concentration is in agreement with the model. From the way in which the methanol concentration varies when the water flow rate is changed, we can infer that the critical value for the flow rate of the film of water is somewhat close to the computed value; the range of water flow rate in which the most considerable reduction of methanol concentration occurs is, in fact, somewhere between 0.2 and $0.8 \mathrm{ml} / \mathrm{min}$. For an additional increase of the water flow rate, methanol concentration does not vary significantly. This is particularly evident for high corona powers, i.e. when the removal of dimethyl sulfide is closer to completion. In these experiments, with the particular geometry and power consumption of the setup in use, methanol could not be totally removed. When dimethyl sulfide is not completely oxidized, i.e. when corona frequency is low, methanol continues being produced along the entire reactor: the final concentration of methanol seems to stabilize to a level of about $5 \mathrm{ppm}$ when water is flowing inside the reactor, and this is independent of its initial concentration without water film. When the SEI is sufficiently high, we expect dimethyl sulfide to oxidize entirely in the first part of the reaction; in this case, methanol production is restricted to this section of the reactor, while the second section can be completely dedicated to the absorption of methanol. The quantity of methanol in the exhaust gases, then, is smaller, reaching a concentration of less than $2 \mathrm{ppm}$. This behavior in the methanol removal suggests that the approximation of $\beta>1$ is still valid, since the critical flow rate can still be inferred by considering $\alpha$ as a critical parameter. However, it also indicates that the actual value of $\beta$ gets closer and closer to 1, i.e. that the effective length of absorption diminishes, when the power of the corona discharge decreases.

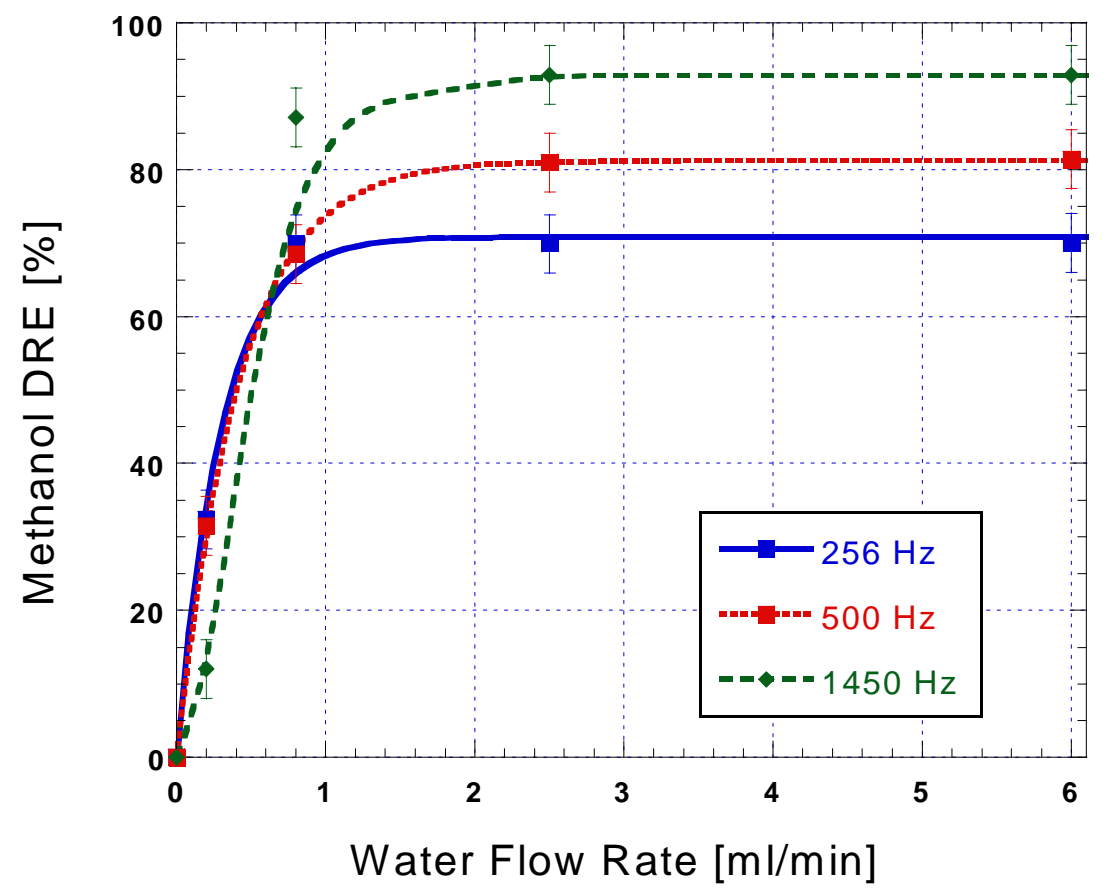

Figure 14. DRE of methanol as byproduct of the oxidation of DMS in the wet corona reactor as a function of the flow rate of the water film.

Different studies found in the literature on the end products of the oxidation of dimethyl sulfide conclude that, for temperatures around $25^{\circ} \mathrm{C}$, the primary product is sulfur dioxide $\left(\mathrm{SO}_{2}\right)$ [14]. In our experiments, the analysis of the byproducts showed that no $\mathrm{SO}_{2}$ was present in the exhaust gas stream, independent of the presence of the water film. 
Some mechanisms for the removal of $\mathrm{SO}_{2}$ are then supposed to take place in the corona reactor. The most significant pathways for the removal of $\mathrm{SO}_{2}$ are the reactions with the active species produced by the discharge and with water, both in liquid and in gas phase.

In order to gain a better understanding performed on the removal of $\mathrm{SO}_{2}$, experiments were in the wet corona reactor by the action of the plasma discharge, of the water film and of the combination of both of them. A gas stream with a flow rate of $1 \mathrm{SLM}$ of dry air and an initial concentration of $\mathrm{SO}_{2}$ equal to $450 \mathrm{ppm}$ was tested. Results obtained from $\mathrm{SO}_{2}$ removal by absorption into water are presented in Figure 15 as function of the flow rate of the film.

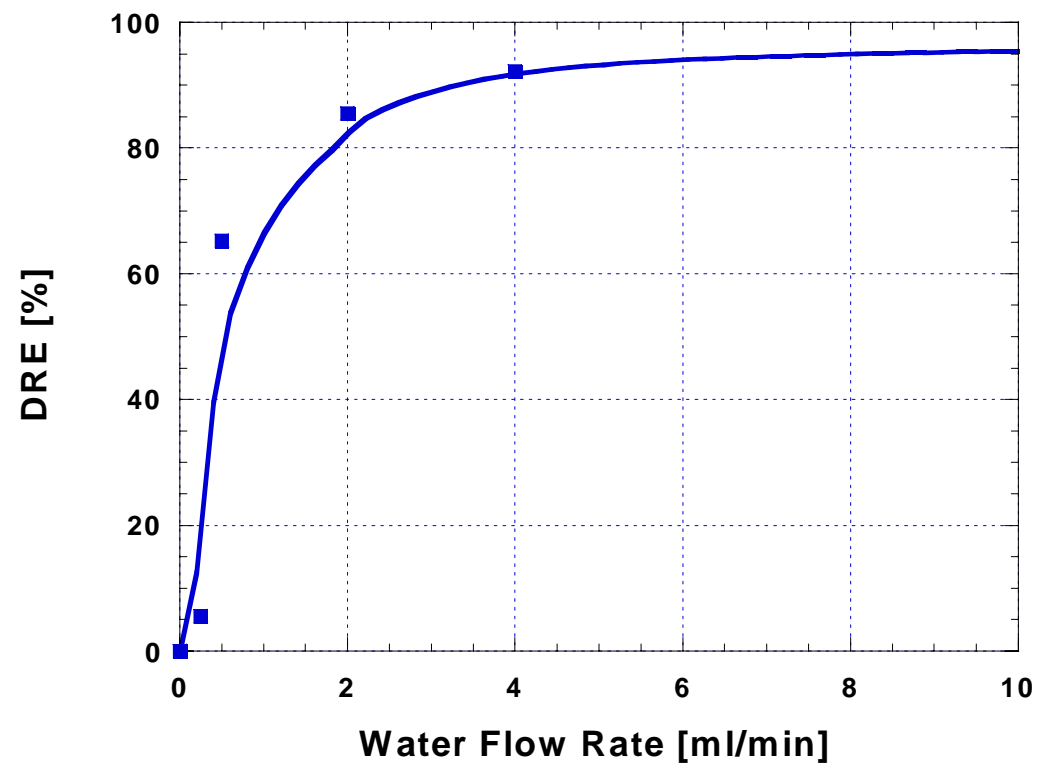

Figure 15. DRE of $\mathrm{SO}_{2}$ by absorption into water as a function of the flow rate of the water film.

From the experimental data it is possible to infer that, in these experimental conditions, the critical value for the water flow rate is around $0.5 \mathrm{ml} / \mathrm{min}$ or lower. From theoretical calculations, a value of the critical water flow rate of about $34 \mathrm{ml} / \mathrm{min}$ is obtained. The difference between calculated value and experimental data can be explained considering that, in addition with its physical solubility (i.e. that, in presence of liquid water, part of the $\mathrm{SO}_{2}$ contained in the gas phase is absorbed into water according with Henry's law), $\mathrm{SO}_{2}$ combines with $\mathrm{H}_{2} \mathrm{O}$ and thus has acid/base chemistry:

$$
\begin{array}{ll}
\mathrm{SO}_{2}(\mathrm{~g})+\mathrm{H}_{2} \mathrm{O} \Leftrightarrow \mathrm{SO}_{2} \cdot \mathrm{H}_{2} \mathrm{O} & K_{H}=1.24 \\
\mathrm{SO}_{2} \cdot \mathrm{H}_{2} \mathrm{O} \Leftrightarrow \mathrm{HSO}_{3}^{-}+H^{+} & p K_{a 1}=1.88 \\
\mathrm{HSO}_{3}^{-} \Leftrightarrow \mathrm{SO}_{3}^{2-}+\mathrm{H}^{+} & p K_{a 2}=7.19
\end{array}
$$

Dissolved $\mathrm{SO}_{2}$ includes hydrated $\mathrm{SO}_{2}$, bisulfite, and sulfite. These forms can be denoted as $\mathrm{S}(\mathrm{IV})$, as follows:

$$
[\mathrm{S}(\mathrm{IV})]=\left[\mathrm{SO}_{2} \cdot \mathrm{H}_{2} \mathrm{O}\right]+\left[\mathrm{HSO}_{3}^{-}\right]+\left[\mathrm{SO}_{3}^{2-}\right]
$$

Based upon the structure of Henry's law, we can define an "effective Henry's law", as:

$$
k_{H}^{*}=\frac{[S(I V)]}{P_{S_{2}}}
$$

where 


$$
k_{H}^{*}=k_{H}\left[1+\frac{k_{a 1}}{\left[H^{+}\right]}+\frac{k_{a 1}}{\left[H^{+}\right]^{2}}\right]
$$

is an "effective Henry's law constant", that actually depends on the $\mathrm{pH}$ of the liquid phase More basic the solution, higher the value of $k_{H}^{*}$ is; however, for every value of the $\mathrm{pH}$ the effective Henry's law constant is higher than the Henry's law constant itself.

$\mathrm{SO}_{2}$ removal in the wet corona discharge was also studied. Figure 16 shows the experimental results for removal of $450 \mathrm{ppm}$ of $\mathrm{SO}_{2}$ from the gas stream in three different experimental configurations, when only the water film, only the corona discharge or the combination of both of them is used. The flow rate of the water film was kept equal to $0.25 \mathrm{ml} / \mathrm{min}$, in order to have a low level of absorption of $\mathrm{SO}_{2}$ into water; in this way, the actual improvement in $\mathrm{SO}_{2}$ removal due to the corona discharge can be pointed out. The removal of $\mathrm{SO}_{2}$ when no water film is flowing into the reactor is completely due to oxidation by the reactive species produced by the plasma discharge. In particular, $\cdot \mathrm{OH}$ is known to be the key species for the oxidation reactions of $\mathrm{SO}_{2}$ at atmospheric conditions. $\cdot \mathrm{OH}$ attacks $\mathrm{SO}_{2}$ with the following reaction:

$$
\cdot \mathrm{OH}+\mathrm{SO}_{2}(+\mathrm{M}) \rightarrow \mathrm{HOSO}_{2}(+\mathrm{M})
$$

$\mathrm{HOSO}_{2}$ is not a kinetically stable species, and rapidly reacts to form $\mathrm{H}_{2} \mathrm{SO}_{4}$. The exact oxidation mechanism is uncertain, but the most evident mechanism acts as follows:

$$
\begin{aligned}
& \mathrm{HOSO}_{2}+\mathrm{O}_{2} \rightarrow \mathrm{HO}_{2}+\mathrm{SO}_{3} \\
& \mathrm{SO}_{3}+\mathrm{H}_{2} \mathrm{O} \rightarrow \mathrm{H}_{2} \mathrm{SO}_{4}
\end{aligned}
$$

The experimental results show the synergetic effect of water film and corona discharge in the elimination of $\mathrm{SO}_{2}$. Let's consider a corona frequency of $1000 \mathrm{~Hz}$. While only about $5 \%$ of $\mathrm{SO}_{2}$ can be removed by the water film itself, the addition, in the plasma reactor, of the film to the discharge accounts for an increase of the removal of $\mathrm{SO}_{2}$ of about $20 \%$ with respect to the case when only the discharge is used. A chemical mechanism that can explain this synergetic effect is the aqueous oxidation of S(IV) by active species such as ozone, hydrogen peroxide and hydroxyl radical. For this mechanism to take place both water in liquid phase and a source of these active species must be present.

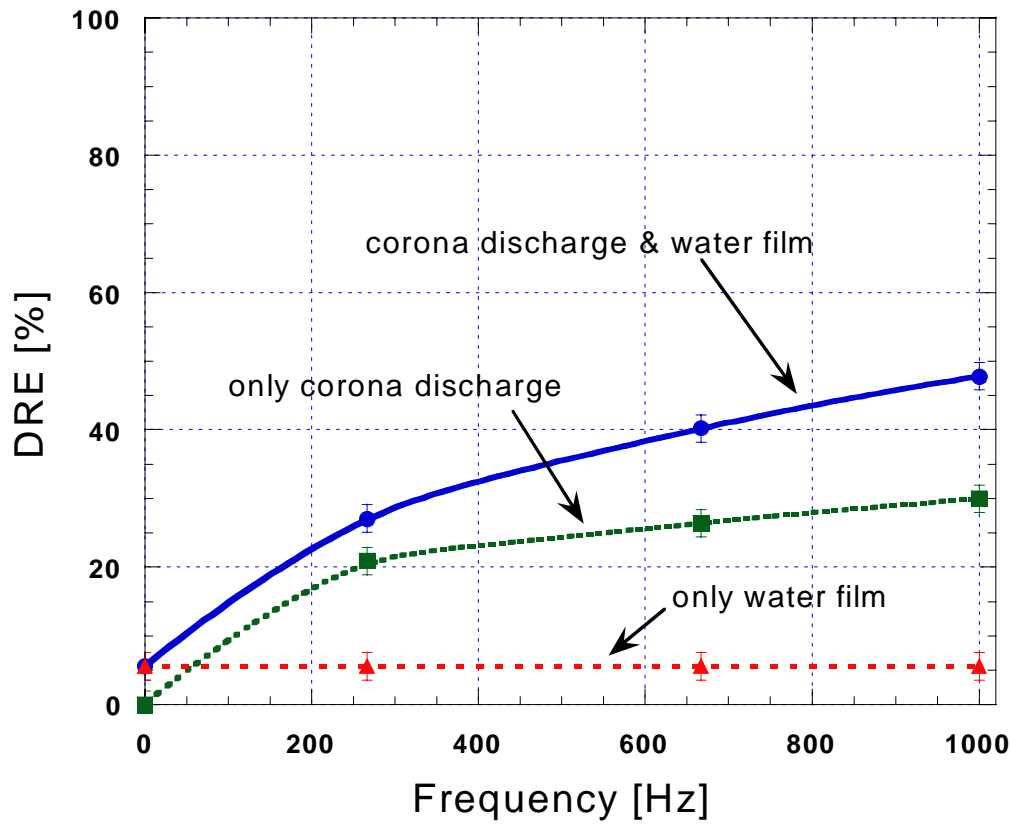

Figure 16. DRE of $\mathrm{SO}_{2}$ in the wet corona reactor.

During the experiments on oxidation of dimethyl sulfide, $\mathrm{SO}_{2}$ was not detected in the exhaust gaseous phase. It is important to notice that in the experiments of DMS oxidation water vapor was always present, given that DMS was 
supplied in water solution and that the solution was vaporized before the injection into the reactor. In this case, then, significant roles in the removal both of the initial contaminant and of the oxidized compounds are played by active species produced in presence of water, such as $\cdot \mathrm{OH}$, and by the reactions with the water molecules in the gas phase. For the experiments run with $\mathrm{SO}_{2}$, on the other hand, no water vapor was introduced.

For the experiments performed with DMS and without water film, the deposition of small droplets on the outlet lines occurred; in presence of water film, this kind of event was not observed. No experimental analyses were undertaken on the amount or on the composition of this mist, but it is reasonable to assume it is due to the mechanism of aerosol formation from $\mathrm{SO}_{2}$ and water vapor molecules. The addition of the water film, then, guarantees that this aerosol containing $\mathrm{H}_{2} \mathrm{SO}_{4}$ is not formed or, at least, is formed in a much smaller amount. This data shows that the solution and the aqueous oxidation of sulfur dioxide become the primary pathways of $\mathrm{SO}_{2}$ removal when water is present in a liquid phase.

\section{Removal of $\alpha$-Pinene by Wet Pulsed Corona Discharge}

The removal of $\alpha$-pinene by combining water film with the gas discharge was also studied. A gas stream containing about $400 \mathrm{ppm}$ of $\alpha$-pinene was treated in the plasma discharge with corona frequency equal to $667 \mathrm{~Hz}$ and constant peak voltage equal to $10 \mathrm{kV}$. Results from the experiments are shown in Table 13. SEI values are fairly constant, equal to $0.47 \mathrm{kWh} / \mathrm{m}^{3}$; it does not seem to depend significantly on the presence of either water vapor in the gas stream or water film on the internal surface of the reactor.

Table 13. DRE [\%] of $\alpha$-pinene and methanol and acetone concentrations [ppm] in the exhaust gas obtained from the treatment of a gas stream containing $300 \mathrm{ppm}$ of $\alpha$-pinene

\begin{tabular}{|c|c|c|c|c|c||}
\hline & \multicolumn{5}{|c|}{ Water Flow Rate [ml/min] } \\
\cline { 2 - 6 } & $\begin{array}{c}\text { No film- } \\
\text { DRY }\end{array}$ & No Film & $\mathbf{2}$ & $\mathbf{1 3}$ & $\mathbf{2 6}$ \\
\hline DRE [\%] & 74.3 & 82.3 & 82.9 & 82.9 & 83 \\
\hline Acet. [ppm] & 22 & 32 & 24 & 14 & 11 \\
\hline Meth. [ppm] & 7 & 8 & 2 & 1 & $<1$ \\
\hline
\end{tabular}

The DRE is influenced by the presence of water vapor: as with butane, the DRE is lower when the gas stream containing $\alpha$-pinene is dry. When no liquid water is introduced in the reactor, the increase in the DRE due to the presence of water vapor is accompanied by an increase in the production of the organic byproducts, such as methanol and acetone.

As expected, for the flow rates used in these experiments, the water film does not affect the removal of $\alpha$-pinene from the gas stream, given its very low solubility in water. On the other hand, the presence of the water film helps in removing the organic byproducts from the gas stream. As in previous experiments, the removal efficiency of methanol and acetone, that are in this case byproducts of oxidation processes, seems to be fairly low and to require a water flow rate that is high compared to the flow rate of the gas. Once more, this is due to the fact that, because of the incomplete removal of $\alpha$-pinene, acetone and methanol keep on being produced along the entire length of the reactor.

\section{LABORATORY TEST CONCLUSIONS}

Atmospheric pressure, non-equilibrium discharges demonstrated to be a practical alternative to traditional techniques for removal of VOC from gas streams containing low concentrations of pollutant compounds. Pulsed corona discharge was tested as non-equilibrium plasma source. A large experimental database on the removal of Volatile Organic Compounds by pulsed corona discharge was produced; studying the effect of pulse frequency, initial VOC concentration, temperature, and humidity on the removal efficiency of different types of VOCs and on the power consumption.

The pulsed corona discharge is a completely non-equilibrium discharge and then guarantees much lower levels of power consumption and $\mathrm{NO}_{\mathrm{x}}$ production. Electrical characteristics of the system and chemical compositions of the 
inlet and outlet gases were determined, in order to verify the viability of this technique in terms of both power consumption and VOC removal efficiency. Chemical measurements on the composition of the exhaust gases after treatment with the pulsed corona discharge give some insight into the actual mechanisms of VOC oxidation; $\cdot \mathrm{OH}$ and $\mathrm{O}_{3}$ initiated oxidation of VOCs appears to be the most probable mechanisms of reaction. The pulsed corona discharge offers high removal efficiency with acceptably low specific energy input; as an example, experimental measurements show (within the limits of the precision of the instruments) that, for concentrations up to $200 \mathrm{ppm}$, dimethyl sulfide can be completely removed from the gas stream using the lowest power (lower than $3 \mathrm{~W}$ ) that can be provided by the power supply. Therefore, a margin for optimization of the experimental system and for further reduction of the energy input is still present.

For diluted streams, the industrial application of this non-equilibrium discharge technology appears competitive with respect to traditional techniques. A commonly used technology such as RTO (regenerative thermal oxidation) requires specific energy input on the level of $0.01 \mathrm{kWh} / \mathrm{m}^{3}$. Power required for these experiments are still slightly higher ( $\left.\mathrm{SEI} \geq 0.02 \mathrm{kWh} / \mathrm{m}^{3}\right)$, but these values will be lowered to levels competitive with RTO, by optimizing and scaling the system to industrial size. The main conclusions that are drawn from the experimental data can be summarized as follows:

- pulsed corona discharge is a feasible technology for VOC removal from the HVLC gas streams produced by the paper industry; high removal efficiency is obtained, with power consumption, in the laboratory scale, only slightly higher than in traditional technologies;

- the power consumption in corona discharge can be easily tuned by varying the frequency of the pulses. This allows for adapting the power consumption to the actual concentration of VOC in the gas stream, with considerable energy saving;

- from the point of view of the industrial application, the heterogeneous system promises to outclass the regular pulsed corona discharge both in terms of power consumption and removal efficiency, considering that not only the compounds initially contained in the gas stream but also the byproducts of oxidation can be easily removed from the gas phase by absorption into water.

- scaling of the system to industrial-like dimensions is also feasible, since the corona discharge can be produced in reactors different from the wire-into-cylinder configuration used for the experiments; a bigger reactor could contain not one but tens of wires or other type of active electrodes.

\section{PULSED CORONA PILOT PLANT}

The objective of the Pilot Plant phase of the project is to develop and to test a Pilot Plant (Fig. 17) with Wet Pulsed Corona Discharge for treatment of VOC emissions in the paper industry. The initial demonstration of the vent emissions control pilot plant operation should be conducted in paper mills owned and operated by the GeorgiaPacific (GP). Pilot plant was developed by the project team: University of Illinois at Chicago (UIC), Drexel University (DU) and the Russian company ECOS.

\section{Figure 17. Trailer mounted Pulsed Corona Pilot Plant}

The uniqueness of the wet corona discharge is a water spray system which supplements the corona providing the benefits of a heterogeneous discharge system. The main effect of water is absorption of soluble components, and any insoluble (non-polar) VOC molecule becomes polar and soluble after interaction with one $\mathrm{OH}$ radical produced in plasma. Another effect of water droplets and water based molecular clusters

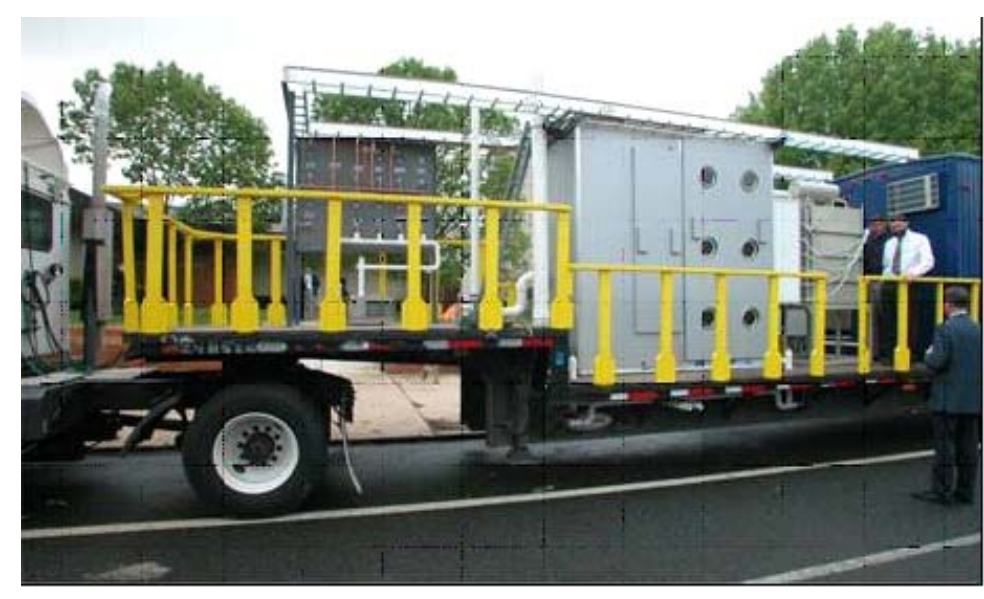
is to promote hydroxyl $\mathrm{OH}^{-}$formation in the water by ion bombardment of the droplets. This process starts with charge exchange on the droplet surface to form positive ions of the water molecules; these ions then reacts with the neutral $\mathrm{H}_{2} \mathrm{O}$ and generates $\mathrm{OH}^{-}$as well as $\mathrm{H}_{3} \mathrm{O}^{+}$ions. VOC oxidation by $\mathrm{OH}^{-}$in the water droplets is also much faster in the liquid phase than in the gas phase. Plasma-stimulated ion-molecular chain reactions are the third liquid 
phase phenomena for intensive promoting of VOC oxidation. The fourth positive effect of droplets is absorption of ozone $\left(\mathrm{O}_{3}\right)$ molecules and consequent relatively fast liquid-phase reactions of VOC oxidation by ozone. All these mechanisms decrease energy cost of VOC oxidation to $\mathrm{CO}_{2}$ and $\mathrm{H}_{2} \mathrm{O}$. The heterogeneous pulse corona is the most useful for diluted streams with relatively low concentration of VOC and also for streams with water soluble VOCs.

\section{$\underline{\text { Pilot Plant Design }}$}

The pilot plant supplies the following three (3) stages of gas treatment:

1. Washing of the exhaust gas stream by a water shower (scrubbing) for diluting and removing soluble VOCs such as methanol and acetone.

2. Exhaust stream treatment by wet, pulse corona discharge for insoluble VOC oxidation and removal of the soluble products from the discharge zone by water flow.

3. Removal of the balance of the ozone and VOC by adsorbent.

The whole gas treatment process will takes place inside the unified reaction chamber (Fig. 18) with complex inner structure. The reaction chamber dimensions (length-width-height) are $2.9 \mathrm{~m}-1.3 \mathrm{~m}-2.56 \mathrm{~m}$.

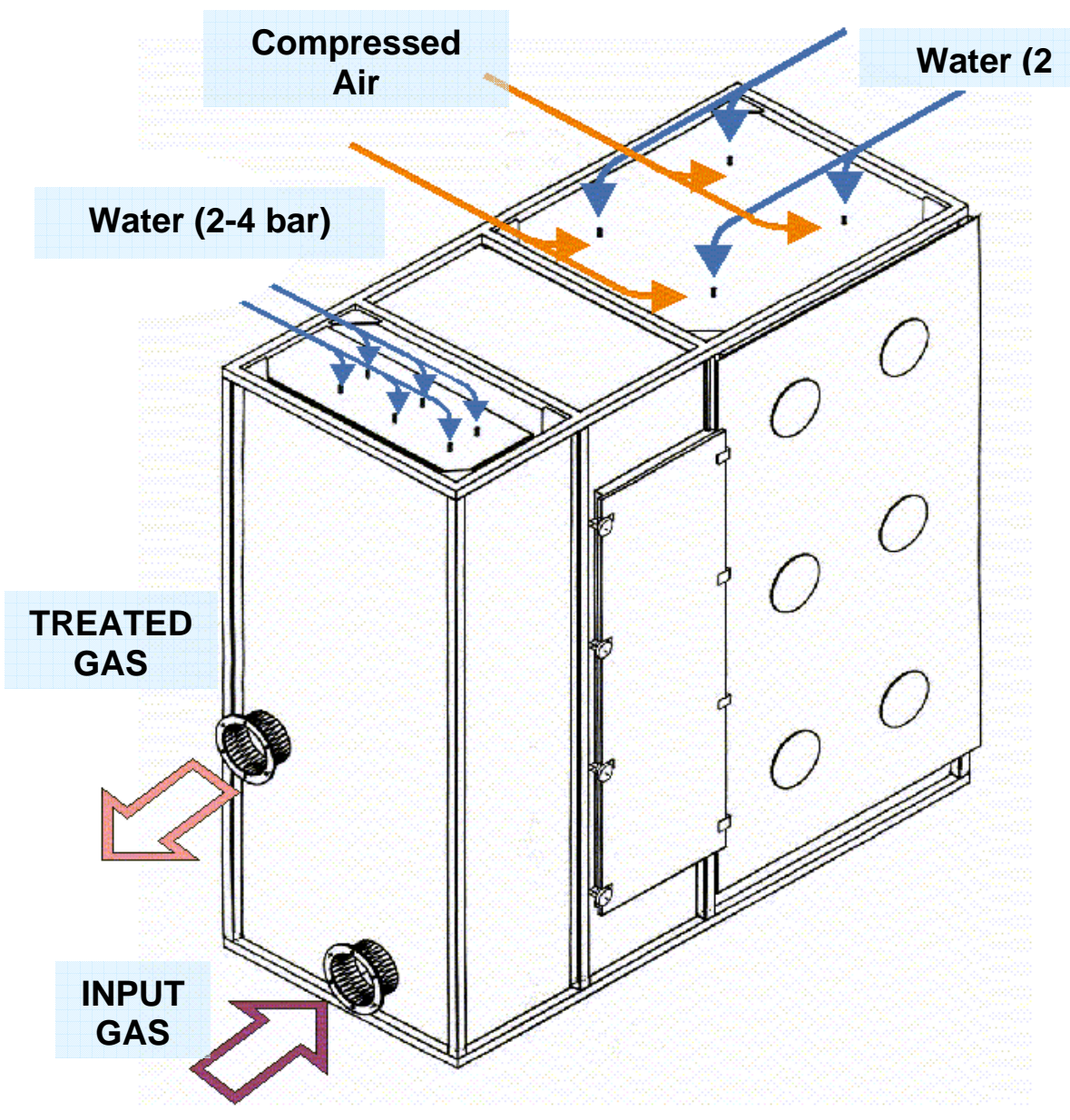

Figure 18. Reaction chamber scheme

The first stage is scrubbing. For maximum soluble VOC removal, the direction of the water motion is opposite to that of the gas stream. Water mass flow rate, droplet size and the velocity of gas stream should be adjusted to provide an effective solution of the soluble VOCs and to prevent droplets carryover by the gas stream. Laboratory experiments and modeling conducted under the current project confirms that it is possible to remove nearly all the soluble VOCs using this technique. The scrubber volume is about $1 \mathrm{~m}^{3}$, total water flow rate through 4 nozzles is about $0.5 \mathrm{~m}^{3} /$ hour. The scrubber is filled with special low density high surface packed bed material. 
In the second stage, the gas stream is treated by the wet corona discharge technique, which includes supplying a water spray into the discharge volume. The direction of water droplet motion in this case is also opposite to the direction of gas stream (in general, relative direction is not so important here because of low relative velocity of gas and droplets and because of soluble components production in the corona volume). Compressed-air atomizers are used for spray formation (4 atomizers with total water flow rate about $0.5 \mathrm{~m}^{3} /$ hour and compressed air flow rate about $20 \mathrm{SCFM}-40 \mathrm{~m}^{3} /$ hour, air pressure 2 bars). According to the laboratory experimental results, the corona discharge power depends on the VOC concentration and gas residence time within the discharge volume. The $90 \%$ removal of terpenes and sulfur components under the expected conditions (see the table above) may be achieved with a relative discharge power of $10-20 \mathrm{~W}$-hour $/ \mathrm{m}^{3}$ if the residence time is $5-10$ seconds. Increasing the residence time to 1 minute results in considerable increase of purification degree; however in this case, the discharge volume chamber becomes unrealistically large. The pilot plant was designed to operate with a gas flow rate of $200-600 \mathrm{~m}^{3} / \mathrm{h}$ (100-300 SCFM). Tested total consumed power of the corona unit is $8.5 \mathrm{~kW}$. For a $75 \%$ efficiency of the pulse corona discharge generation, the discharge power should be about $6.4 \mathrm{~kW}$.

The pulse corona discharge unit consists of a high-frequency converter with an intermediate frequency of $25 \mathrm{kHz}$ on the base of field (IGBT) transistors, pulse high-voltage transformers, work capacitance and special high-voltage selffiring discharge gap for high voltage pulse formation on the corona electrodes. Discharge power is regulated by stepwise changing of the pulse repetition frequency in the rage $20-100 \%(20 \%, 40 \%, 60 \%, 80 \%$, and $100 \%)$. The main parameters of the corona discharge are the following: voltage peak $35-45 \mathrm{kV}$, pulse repetition frequency up to $1 \mathrm{kHz}$, and pulse duration of 200-250 ns. The structure of the pulsed corona discharge electrodes consists of alternate rows of grounded and high-voltage electrodes (e.g. wires). Such a structure provides transparency of the discharge volume for the water spray. Corona discharge zone is formed by 12 corona blocks (Fig. 19) installed in three layers. The discharge volume is about $3.6 \mathrm{~m}^{3}$.

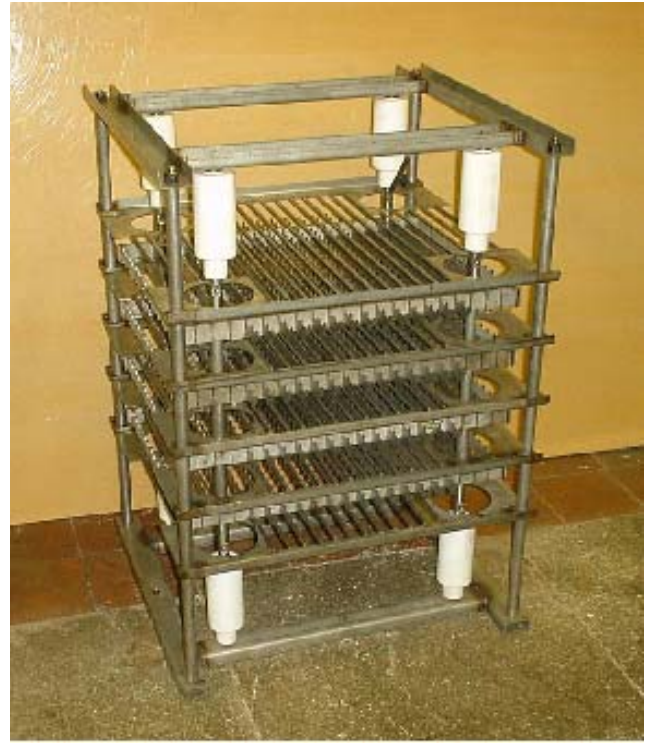

Figure 19. Pulsed corona block

Figure 20 demonstrates appearance of the pulsed corona discharge in the Pilot Plant. Brightness of this picture is enhanced significantly. In reality it is possible to see the discharge only when the surrounding lights are off and the corona has maximal power.

Figure 20. Pulsed corona discharge in the Pilot Plant

The last cleaning stage includes adsorption and oxidation of any remaining VOCs on the filter. This filter is activated charcoal particles of $3 \mathrm{~mm}$ size in layers of $2 \mathrm{~cm}$ thickness. Total area of the layers is about $2 \mathrm{~m}^{2}$. Gas velocity through the filter is about $1 \mathrm{~m} / \mathrm{s}$. This filter should provide complete removal of any remaining VOCs, ozone and nitrogen oxides.

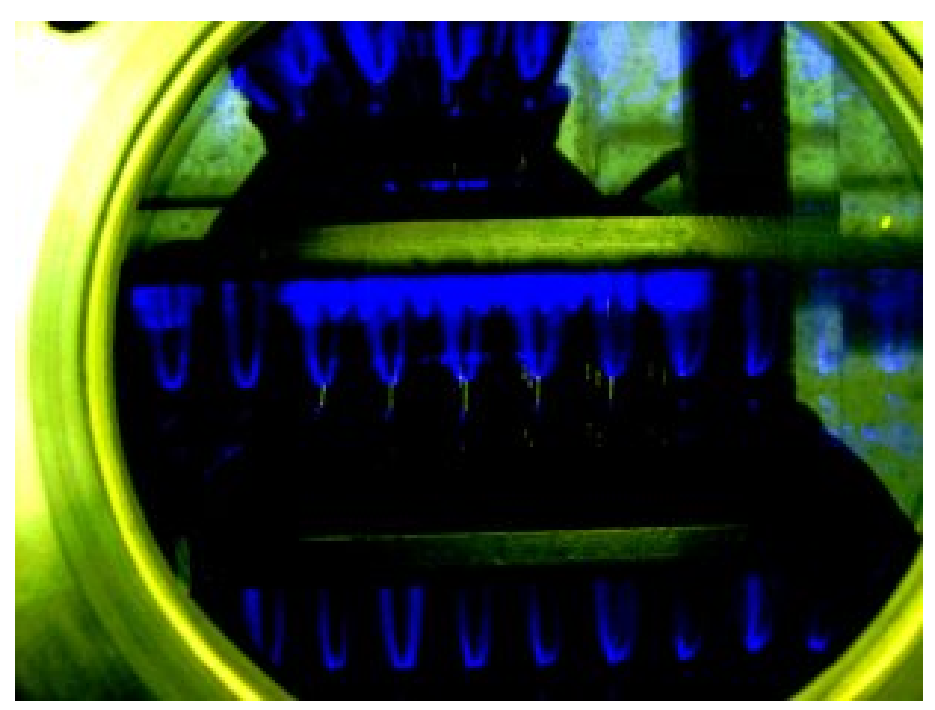

The following simplified (for industrial use) pilot plant model was designed in order to simulate pilot plant behavior in different conditions and to obtain all required information for the creation of the control system. It is important to 
notice that detailed simulation of the processes in each of the pilot plant's sections was not the main goal. The main goal was to develop an instrument, which allows us to simulate overall behavior of the system with the precision, which is enough for the creation of the effective control system.

\section{Pilot Plant Model}

In order to develop the precise model the system we would need a full description of chemical kinetics of the system, which usually requires more than a hundred equations of chemical reactions. In order to simplify chemical kinetics of the system we made a few but very strong assumptions:

1) All VOC compounds can be combined in two categories: a) soluble VOC, b) insoluble VOC;

2) All soluble as well as all insoluble compounds have the similar properties, ant it allows us to account in our simulations only two different VOCs: $s$ - soluble and $u$ - insoluble.

3) There are only two active elements in corona chamber: ozone and $\mathrm{OH}$ molecules.

The systems of equations are different in each of the blocks of the pilot plant, but we still can be consistent and use the same terminology for all the three chambers:

$\mathrm{W} \quad\left[\mathrm{J} / \mathrm{cm}^{3}\right] \quad$ corona power per volume of treated gas

$\mathrm{C}_{\mathrm{sg}} \quad[\mathrm{ppm}] \quad$ concentration of soluble compounds in gaseous phase

$\mathrm{C}_{\mathrm{sl}} \quad[\mathrm{ppm}] \quad$ concentration of soluble compounds in liquid phase

$\mathrm{C}_{\mathrm{ig}} \quad[\mathrm{ppm}]$

$\mathrm{C}_{\mathrm{oh}} \quad[\mathrm{ppm}]$

$\mathrm{C}_{\mathrm{o} 3 \mathrm{~g}} \quad[\mathrm{ppm}]$

$\mathrm{C}_{\mathrm{o} 31} \quad[\mathrm{ppm}]$

D $\quad\left[\mathrm{cm}^{2} / \mathrm{s}\right]$

$\mathrm{H} \quad$ [non-dimensional]

$\mathrm{V} \quad\left[\mathrm{cm}^{3}\right]$

$1 \quad[\mathrm{~cm}]$

$\mathrm{x} \quad[\mathrm{cm}]$

$\mathrm{S} \quad\left[\mathrm{cm}^{2}\right]$

$\mathrm{r}_{(\mathrm{c}, \mathrm{s})} \quad[\mathrm{cm}]$

$\mathrm{Q}_{\mathrm{g}} \quad\left[\mathrm{cm}^{3} / \mathrm{s}\right]$

$\mathrm{Q}_{\mathrm{w}(\mathrm{c}, \mathrm{s})} \quad\left[\mathrm{cm}^{3} / \mathrm{s}\right]$

$\mathrm{V}_{\mathrm{g}(\mathrm{c}, \mathrm{s})} \quad[\mathrm{cm} / \mathrm{s}]$

$\mathrm{V}_{\mathrm{w}(\mathrm{c}, \mathrm{s})} \quad[\mathrm{cm} / \mathrm{s}]$

$\mathrm{V}_{\mathrm{r}(\mathrm{c}, \mathrm{s})} \quad[\mathrm{cm} / \mathrm{s}]$

$\mathrm{K}_{\mathrm{a} \_\mathrm{b}} \quad\left[\mathrm{ppm}^{-1} \mathrm{~s}^{-1}\right]$

$\mathrm{K}_{\mathrm{oh}, 03} \quad\left[\mathrm{ppm} \cdot \mathrm{cm}^{3} / \mathrm{s} / \mathrm{J}\right]$

concentration of insoluble compounds (always in gaseous phase)

concentration of $\mathrm{OH}$ molecules (always in gaseous phase)

concentration of $\mathrm{O}_{3}$ molecules in gaseous phase

concentration of $\mathrm{O}_{3}$ molecules in liquid phase

diffusion coefficient (subscripts are the same as in concentration)

Henry constant (subscripts are the same as in concentration)

volume of the chamber

length of the chamber

positive coordinate calculated from the top of the chamber

cross-section of the chamber

$1 / 2$ of the distance between droplets of water (c - corona, $\mathrm{s}$ - scrubber)

flow rate of the gas (constant throughout the system)

flow rate of the water ( $\mathrm{c}$ - corona, $\mathrm{s}$ - scrubber)

speed of the gas (c - corona, $\mathrm{s}$ - scrubber)

speed of the water (c - corona, $\mathrm{s}$ - scrubber)

relative speed of the water with respect to the speed of the gas

coefficient of the rate of the chemical reaction between compounds $a$ and $b$

efficiency of corona in active particles $\left(\mathrm{OH}, \mathrm{O}_{3}\right)$ production

\section{Equations for the corona unit}

$$
\frac{d C_{o h}}{d t}=\left(K_{o h} W-K_{i_{-} o h} C_{i} C_{o h}-K_{s g_{-} o h} C_{s g} C_{o h}-C_{o h_{-} o h} C_{o h}^{2}\right)
$$

This equation shows that molecules of $\mathrm{OH}$ are generated by corona and then they disappear in reaction s with insoluble and soluble components and also in reactions with each other.

2) $\frac{d C_{i}}{d t}=\left(-K_{i_{-} o h} C_{i} C_{o h}\right)$

There is no production of insoluble components in the system, and their concentration is decreasing with the time because of their reactions with the molecules of $\mathrm{OH}$.

$$
\frac{d C_{s g}}{d t}=\left(A_{1} K_{i_{-} o h} C_{i} C_{o h}-K_{s g_{-} o h} C_{s g} C_{o h}-\frac{D_{s g}}{r_{c}^{2}}\left(C_{s g}-\frac{C_{s l}}{H_{s}}\right)\right)
$$

Soluble components are created in reaction between molecules of $\mathrm{OH}$ and insoluble components (Coefficient A1 shows that it is possible, that the number of molecules of soluble components can be different from the number of molecules of $\mathrm{OH}$ and insoluble components involved in the reaction). The reduction of the concentration of the 
soluble components happens because of heir reactions with $\mathrm{OH}$ molecules and because of they are dissolved by the water.

$$
\frac{d C_{o 3 g}}{d t}=\left(K_{o 3} W-\frac{D_{o 3 g}}{r_{c}^{2}}\left(C_{o 3 g}-\frac{C_{o 3 l}}{H_{o 3}}\right)\right)
$$

Ozone is generated by the corona and then it dissolves in the water. There is a possibility that ozone is also involved in reactions with insoluble components in gaseous phase but this hypothesis is on stage of development.

$$
\frac{d C_{s l}}{d t}=\left(\frac{D_{s g}}{r_{c}^{2}}\left(C_{s g}-\frac{C_{s l}}{H_{s}}\right)-K_{s l_{-} o 3 l} C_{s l} C_{o 3 l}+v_{r c} \frac{d C_{s l}}{d x}\right)
$$

The concentration of soluble components in liquid phase increases while soluble components in gaseous phase dissolve in the water, reduces because of the reactions with ozone in liquid phase, and there is also an increase of concentration due to transfer of the liquid from top to bottom of the corona chamber.

$$
\frac{d C_{o 3 l}}{d t}=\left(\frac{D_{o 3 g}}{r_{c}^{2}}\left(C_{o 3 g}-\frac{C_{o 3 l}}{H_{o 3}}\right)-K_{s l_{-} o 3 l} C_{s l} C_{o 3 l}+v_{r c} \frac{d C_{o 3 l}}{d x}\right)
$$

Ozone in liquid phase behaves exactly like soluble components in liquid phase.

7) $x=v_{g c} t$

As soon as all the above equations are derived in the assumption that the observer is in the system of the gas, all the above equations can be transformed into equations of time or coordinate only using the equation \#7.

\section{Equations for the scrubber chamber}

The overall system of the scrubber is much simpler than the system of the corona because there are no chemical reactions associated with this unit. The only process which we observe is the dissolution of the soluble components. Thus, the system of equations for scrubber is the following:

1)

$$
\begin{aligned}
& \frac{d C_{s g}}{d t}=\left(-\frac{D_{s g}}{r_{s}^{2}}\left(C_{s g}-\frac{C_{s l}}{H_{s}}\right)\right) \\
& \frac{d C_{s l}}{d t}=\left(\frac{D_{s g}}{r_{s}^{2}}\left(C_{s g}-\frac{C_{s l}}{H_{s}}\right)+v_{r s} \frac{d C_{s l}}{d x}\right)
\end{aligned}
$$

Figure 21 demonstrates how the model describes the dependence of substance concentrations along the discharge chamber.

\section{$\underline{\text { Pilot Plant Test }}$}

Planned on-site Pilot Plant test has the main goal a technology validation from the economical and robustness points of view. Design of the Pilot plant permits relatively easy to make scale-up of the technology. The test supposed to be run of the Georgia-Pacific owned facility.

\section{ACKNOWLEDGEMENT}

This research was funded in parts by Office of Industrial Technology of the Department of Energy, by GeorgiaPacific Corporation, by University of Illinois at Chicago, by Drexel University and by ECOS Ltd. 


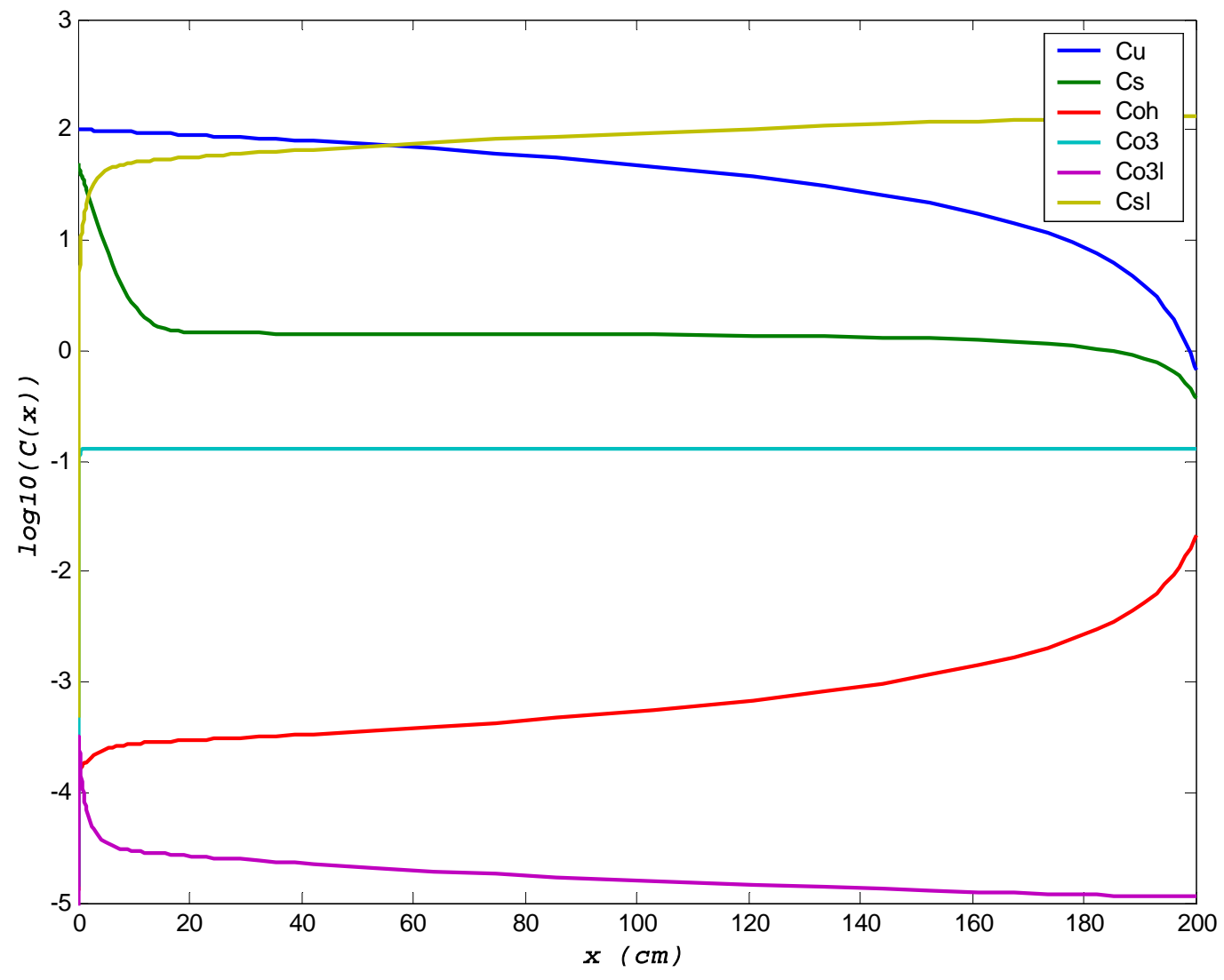

Figure 21. Dependence of substance concentrations along the discharge chamber according to the developed model

\section{REFERENCES}

1. Paur, H.R.: Removal of Volatile Hydrocarbons from Industrial Off-Gas. Non-Thermal Plasma Techniques for Pollution Control, eds. B.M. Penetrante and S.E. Schultheis, pp.277-289. Berlin, Springer-Verlag, 1992

2. Sun, B., Sato, M., Clements, J.S.: Use of Pulsed High-Voltage Discharge for Removal of Organic Compounds in Aqueous Solution. Journal of Applied Physics, 32:1908-1915, 1999

3. Rosocha, L.A. et al.: Treatment of Hazardous Organic Wastes using Silent Discharge Plasmas. Non-Thermal Plasma Techniques for Pollution Control, eds. B.M. Penetrante and S.E. Schultheis, pp.281-311. Berlin, SpringerVerlag, 1992

4. Fridman, A., Rusanov, V.: Theoretical Basis of Non-Equilibrium Near Atmospheric Pressure Plasma Chemistry. Pure and Applied Chemistry. 66:1267-1274, 1994

5. Czernichowsky, A., Labbé, Ph., Laval, F., Lesueur, H.: Plasma-Assisted Cleaning of Flue Gas from a Sooting Combustion. Emerging Technologies in Hazardous Waste Management V. American Chemical Society, pp. 144153 
6. Penetrante, B.M. et al.: Non-Thermal Plasma Techniques for Abatement of Volatile Organic Compounds and Nitrogen Oxides. Preprint for the Workshop on Plasma Based Environmental technologies. Berlin, 1995

7. Czernichowsky, A., Fridman, A., Chapelle, J., Liventsov, V.: The Gliding Arc as Non-Equilibrium High-Power Atmospheric Pressure Discharge. Preprint of the Kurchatov Institute Russian Research Center IAE-5892/6, Moscow, 1995

8. Mutaf Yardimci, O., Saveliev, A.A., Fridman, A.A., Kennedy, L.A.: Thermal and Nonn-Thermal Regimes of Gliding Arc Discharge in air Flow. Journal of Applied Physics. 87:1632-1641, 2000

9. Penetrante, B.M., Bardsley, J.N., Hsiao, M.C.: Kinetic Analysis of Non-Thermal Plasmas Used for Pollution Control. Japanese Journal of Applied Physics. 36:5007-5017,

10. Penetrante, B.M.: Preface to Non-Thermal Plasma Techniques for Pollution Control, eds. B.M. Penetrante and S.E. Schultheis, pp.33-42. Heidelberg, Springer-Verlag, 1992

11. Dalaine, V. Cormier, J.M. Lefaucheux, P.: A Gliding Discharge Applied to $\mathrm{H}_{2} \mathrm{~S}$ Destruction. Journal of Applied Physics. 83:2435-2441, 1997

12. Penetrante, B.M., Bardsley, J.N., Hsiao, M.C., Merritt, B.T., Vogtlin, G.E., Wallman, P.H.: Electron Beam and Pulsed Corona Processing of Volatile Organic Compounds in Gas Streams. Pure and Applied Chemistry. 68, 10831087, 1996

13. Sun, B., Sato, M., Clements, J.S.: Optical Study of Active Species Produced by a Pulsed Streamer Corona Discharge in Water. Journal of Electrostatics. 39:189-202, 1997

14. Turnipseed, A.A., Barone, S.B., Ravishenkara, A.R.: Reaction of $\mathrm{OH}$ with Dimethyl Sulfide (DMS). 1.Equilibrium Constants for OH+DMS Reaction and the Kinetics of the OH·DMS $+\mathrm{O}_{2}$ Reaction. Journal of Physical Chemistry. 100:14694-14702, 1996

15. Turnipseed, A.A., Barone, S.B., Ravishenkara, A.R.: Reaction of OH with Dimethyl Sulfide. 2. Products and Mechanisms. Journal of Physical Chemistry. 100:14703-14713, 1996

16. Jenkin, M.E., Shallcross, D.E., Harvey, J.N.: Development and Application of a Possible Mechanism for the Generation of Cis-Pinic Acid from the Ozonolysis of $\alpha$ - and $\beta$-Pinene. Atmospheric Environment. 34:2837-2850, 2000

17. Vereecken, L., Peeters, J.: Theoretical study of the Formation of Acetone in the OH-Initiated Atmospheric Oxidation of $\alpha$-Pinene. Journal of Physical Chemistry A. 104:11140-11146, 2000

18. "The Technical and Economic Feasibility of Using Low-Temperature Plasma to Treat Gaseous Emissions from Pulp Mills and Wood Products Plants", John B. L. Harkness and Alexander A. Fridman, NCASI Technical Bulletin No. 795, September 1999.

19. Mario G. Sobacchi, Alexei V. Saveliev, A. A. Fridman, A. F. Gutsol, Lawrence A. Kennedy, "Experimental Assessment of Pulsed Corona Discharge for Treatment of VOC Emissions", Plasma Chemistry and Plasma Processing, Vol. 23, No. 2, 2003, p. 347-370. 